\title{
Las situaciones atmosféricas lluviosas en Navarra
}

\author{
Javier María Pejenaute Goñi *
}

\section{INTRODUCCIÓN}

Es cierto que dentro del campo de la climatología, las precipitaciones constituyen uno de los elementos más importantes por la influencia que tienen en la vida de los hombres y en los recursos económicos de un país. En los últimos años se han sucedido en nuestra Comunidad irregularidades pluviométricas, sequias fuertes que alternan con aguaceros de gran intensidad y una diferenciación extensa entre las distintas comarcas navarras con respecto a esta variable. Por todo ello me he planteado como objetivo en este artículo al estudio de los contrastes comarcales que las diversas situaciones atmosféricas originan en nuestro territorio.

Navarra es una comunidad rica en contrastes climáticos. En efecto, del Pirineo a la Ribera se suceden la mayor parte de los matices climáticos de la Península. Los Valles Húmedos gozan de un clima templado y húmedo; por el contrario en la parte meridional aparecen las caracteristicas propias de un medio semiárido que se extiende por el Valle del Ebro. Entre ambos se suceden multitud de matices originados por la disminución de las lluvias desde la parte septentrional a la meridional. Finalmente las montañas introducen nuevas variaciones, como ocurre en el clima subalpino de Pirineos, que aumentan considerablemente este mosaico de microclimas existentes en nuestro territorio. Así pues, la re-

\footnotetext{
* Profesor Tutor. UNED.
} 
percusión de las distintas advecciones lluviosas sobre nuestro suelo adquiere una gran importancia.

Para su realización se ha anotado diariamente el tipo de situación atmósferica para el período 1983-1986 teniendo en cuenta para la clasificación primeramente el mapa de superficie y posteriormente la topografia de $500 \mathrm{mb}$. Se han distinguido diez situaciones atmosféricas: Noroeste (NW), isobaras e isohipsas en sentido NW-SE; Norte (N), y isobaras e isohipsas en sentido meridiano N-S.; Nordeste (NE), isobaras en sentido NE-SW con anticiclón situado al Norte de nuestra área de estudio; Este/ Sudeste $(E / S E)$ isobaras en sentido $E-W$ e isohipsas de dirección variable; Sur/Sudoeste ( $S / S W$ ), isobaras e isohipsas en sentido SW-NE, y $S$ $\mathrm{N}$; Oeste (W), isobaras e isohipsas en el sentido de los paralelos; Oesteanticiclónico (w/ant), anticiclón en superficie y circulación del oeste en altura; Baja fría (BJ), borrasca en superficie y vaguada o gota fría en altura; Baja térmica (BT), bajas relativas en superficie y dorsal en altura; Pantano barométrico $(\mathrm{PB})$, ausencia de gradiente bárico y presión próxima a la normal.

Posteriormente se han obtenido los porcentajes de dias de precipitación y de precipitación total que aporta cada una de las situaciones atmosféricas en diez observatorios navarros elegidos por su fiabilidad, ausencia de lagunas y situación estratégica dentro de cada una de las comarcas navarras más representantivas. Después se ha analizado cada situación por separado y para su explicación se sigue este esquema: Breve referencia a la situación atmosférica (Masas de aire, centros de acción, posición de Navarra); análisis de las frecuencias porcentuales (dias de lluvia y aportación al total) de cada situación en las distintas comarcas navarras; estudio de un día concreto con esta situación (Estudio de los mapas de superficie, $500 \mathrm{mb}$ y $300 \mathrm{mb}$ y resultados en los observatorios navarros) y tiempo que se dio en el Norte, Centro y Sur de Navarra. Se han utilizado veinte observatorios navarros, diez de ellos principales y otros diez de apoyo, y cuatro completos correspondientes a ciudades cercanas (Cuadro I).

\section{SITUACIÓN DEL NOROESTE (NW)}

La prolongación del anticiclón atlántico por medio de una apófisis hasta latitudes altas, generalmente Escocia o Islandia, debido a descargas polares de fin de familia, y la formación de centros ciclonales en Europa Central, origina una circulación del Noroeste, que normalmente 
CUADRO I. RED DE ESTACIONES UTILIZADAS'

\begin{tabular}{|c|c|c|c|c|c|}
\hline & \multirow{2}{*}{ OBSERVATORIOS } & \multirow{2}{*}{ SECTOR } & \multirow{2}{*}{ ALT. (m) } & \multicolumn{2}{|c|}{ COORDENADAS } \\
\hline & & & & LAT. & LONG. \\
\hline 1. & Articutza & Nav. Húmeda & 300 & $43^{\circ} 13^{\prime} \mathrm{N}$ & $1^{\circ} 54^{\prime} E$ \\
\hline 2 . & Betelu & Nav. Húmeda & 230 & $43^{\circ} 02^{\prime} \mathrm{N}$ & $1^{\circ} 43^{\prime} E$ \\
\hline 3. & Sumbilla & Nav. Húmeda & 120 & $43^{\circ} 10^{\prime} \mathrm{N}$ & $2^{\circ} 01^{\prime} \mathrm{E}$ \\
\hline 4. & Errazu & Nav. Húmeda & 353 & $43^{\circ} 10^{\prime} \mathrm{N}$ & $2^{\circ} 14^{\prime} \mathrm{E}$ \\
\hline 5 . & Eugui-Esteríbar & Nav. Pirenaica & 615 & $42^{\circ} 58^{\prime} \mathrm{N}$ & $2^{\circ} 10^{\prime} \mathrm{E}$ \\
\hline 6. & Valcarlos & Nav. Pirenaica & 365 & $43^{\circ} 06^{\prime} \mathrm{N}$ & $2^{\circ} 23^{\prime} E$ \\
\hline 7 . & Roncesvalles & Nav. Pirenaica & 963 & $43^{\circ} 01^{\prime} \mathrm{N}$ & $2^{\circ} 22^{\prime} E$ \\
\hline 8. & Abaurrea Alta & Nav. Pirenaica & 1.047 & $42^{\circ} 54^{\prime} N$ & $2^{\circ} 29^{\prime} \mathrm{E}$ \\
\hline 9 . & Esparza Salazar & Nav. Pirenaica & 693 & $42^{\circ} 51^{\prime} \mathrm{N}$ & $2^{\circ} 35^{\prime} \mathrm{E}$ \\
\hline 10. & Urzainqui & Nav. Pirenaica & 717 & $42^{\circ} 50^{\prime} \mathrm{N}$ & $2^{\circ} 44^{\prime} E$ \\
\hline 11. & Alsasua. & Cuencas Int. & 520 & $42^{\circ} 54^{\prime} \mathrm{N}$ & $1^{\circ} 31^{\prime} \mathrm{E}$ \\
\hline 12. & Irurzun & Cuencas Int. & 470 & $42^{\circ} 55^{\prime} \mathrm{N}$ & $1^{\circ} 52^{\prime} \mathrm{E}$ \\
\hline 13. & Pamplona-Noaín & Cuencas int. & 453 & $42^{\circ} 46^{\prime} N$ & $2^{\circ} 03^{\prime} E$ \\
\hline 14. & Goñi & Cuencas Int. & 900 & $42^{\circ} 51^{\prime} \mathrm{N}$ & $1^{\circ} 47^{\prime} \mathrm{E}$ \\
\hline 15. & Alloz & Nav. Media & 475 & $42^{\circ} 42^{\prime} \mathrm{N}$ & $1^{\circ} 45^{\prime} \mathrm{E}$ \\
\hline 16. & Olite & Nav. Media & 383 & $42^{\circ} 29^{\prime} \mathrm{N}$ & $2^{\circ} 02^{\prime} E$ \\
\hline 17. & Yesa & Nav. Media & 489 & $42^{\circ} 37^{\prime} \mathrm{N}$ & $2^{\circ} 30^{\prime} \mathrm{E}$ \\
\hline & San Adrián & Ribera Nav. & 318 & $42^{\circ} 20^{\prime} \mathrm{N}$ & $1^{\circ} 45^{\prime} \mathrm{E}$ \\
\hline 19. & Carcastillo & Ribera Nav. & 340 & $42^{\circ} 22^{\prime} N$ & $2^{\circ} 13^{\prime} \mathrm{E}$ \\
\hline 20. & Fitero .... & Ribera Nav. & 421 & $42^{\circ} 03^{\prime} \mathrm{N}$ & $1^{\circ} 50^{\prime} \mathrm{E}$ \\
\hline
\end{tabular}

1 También se han utilizado las siguientes estaciones completas: San Sebastián-Igueldo (258 mm y $4318^{\prime} \mathrm{N}-1$ 39' E), San Sebastián-Aeropuerto ( $3 \mathrm{~m}$ y $4322^{\prime} \mathrm{N}-154^{\prime} \mathrm{E}$ ), LogroñoAgoncillo (366 m y $4227^{\prime} \mathrm{N}-124^{\prime} \mathrm{E}$ ) y Zaragoza-Aeropuerto (247 m y $4139^{\prime} \mathrm{N}-100^{\prime} \mathrm{W}$ ).

circula siguiendo la ruta Golfo de Vizcaya a Mediterráneo y atrae masas de aire frías y húmedas, que en contacto con las más recalentadas produce una sucesión de frentes fríos que dan lugar, cuando las circunstancias son propicias, a fuertes chubascos, debido al levantamiento que el aire frio origina al entrar en cuña. La vía 5 de Van Bebber, que afecta a Navarra, produce importantes lluvias con esta situación (Pedelaborde, 1970, 112).

Las situaciones de cuarto cuadrante originan los más altos porcentajes de días de precipitación y de cantidad de agua de lluvia aportada en Navarra Húmeda, Pirineos y Corredor del Araquil. En Navarra Húmeda proporciona la cuarta parte de los días de lluvia anuales y la tercera parte de la cantidad total de precipitación total recogida; no existen apenas diferencias entre los Valles Húmedos Occidentales (Articutza) y la Cuenca del Bidasoa (Sumbilla). Los flujos del Noroeste son también 
muy lluviosos en los Pirineos y en el Corredor del Araquil, si bien los valores descienden con respecto a Navarra Húmeda; los Pirineos Centrales (Eugui) tienen similares valores que los Pirineos Orientales (Abaurrea Alta) y ligeramente superiores a los del Corredor del Araquil (Cuadro II).

Sin lugar a dudas las masas de aire inestables procedentes del Cantábrico cargadas de humedad en su largo recorrido por el océano, al llegar a Navarra, se refuerzan y, obligadas a estancarse y ascender por los primeros contrafuertes montañosos (Macizos de Cinco Villas y Quinto Real y Cadena Divisoria), proporcionan días de lluvia, lo cual se traduce en una cantidad de precipitación importante con esta situación. La orientación de estas montañas navarras es favorable al flujo del Noroeste, conforme avanzan estas masas de aire hacia el interior, al ir pasando los Valles Pirenaicos, cuyas montañas actúan de sucesivas pantallas y pese a la mayor altura, van perdiendo progresivamente su efectividad pluviométrica, si bien todavía la conservan en los Pirineos Orientales Navarros.

En el resto de Navarra este flujo es importante en cuanto a precipitaciones se refiere, sin embargo ya no es el más lluvioso, aunque sí de los que más. Los valores experimentan un descenso hacia el Este y Sur. En las Cuencas Intermedias los porcentajes se sitúan próximos al 20 por 100. Las Sierras Exteriores actúan como un nuevo freno a las influencias

\section{CUADRO II. PORCENTAJE DE DÍAS DE PRECIPITACIÓN Y DE PRECIPITACIÓN TOTAL QUE APORTA LA SITUACIÓN NW}

(1983-1986)

\begin{tabular}{|c|c|c|c|c|c|c|c|c|c|c|}
\hline \multirow{2}{*}{ OSSERVATORIOS } & \multicolumn{2}{|c|}{ PRIMAVERA } & \multicolumn{2}{|c|}{ VERANO } & \multicolumn{2}{|c|}{ OTONOO } & \multicolumn{2}{|c|}{ INVIERNO } & \multicolumn{2}{|c|}{ ANUAL } \\
\hline & (1) & (2) & (1) & (2) & (1) & (2) & (1) & (2) & (1) & (2) \\
\hline 1. Articutza & 23,6 & 28,9 & 24,7 & 23,9 & 19,6 & 28,1 & 29,7 & 49,6 & 24,4 & 32,3 \\
\hline 2. Sumbilla & 24,1 & 29,8 & 22,2 & 20,8 & 24,4 & 28,9 & 32,6 & 45,6 & 25,6 & 31,3 \\
\hline 3. Eugui-Esteribar & 22,1 & 29,9 & 22 & 23,3 & 19,4 & 20,4 & 29 & 42 & 23,1 & 28,9 \\
\hline 4. Abaurrea Alta. & 26,8 & 25,4 & 20 & 21,1 & 17,8 & 16,1 & 30,2 & 34,1 & 23,7 & 24,1 \\
\hline 5. Alsasua & 24 & 26,4 & 18,7 & 18,5 & 20,2 & 22,2 & 28,4 & 27,6 & 22,8 & 23,7 \\
\hline 6. Pamplona-Noain .. & 23,4 & 18,7 & 16,7 & 21,3 & 13,7 & 16,8 & 31,2 & 25,1 & 21,2 & 20,2 \\
\hline 7. Yesa. & 20,3 & 18,3 & 16,9 & 16,7 & 13,7 & 11,7 & 29,4 & 29,9 & 20,1 & 19,1 \\
\hline 8. Olite & 17,8 & 16,6 & 14,7 & 9,5 & 9,3 & 2,3 & 26 & 20,7 & 17 & 12,2 \\
\hline 9. Carcastillo & 19,7 & 16,3 & 14,6 & 6,5 & 7,6 & 3,7 & 26 & 19,3 & 17 & 11,4 \\
\hline 10. Fitero & 19,2 & 13 & 12,2 & 8,8 & 2,5 & 2,5 & 23,1 & 17 & 14,3 & 10,3 \\
\hline
\end{tabular}

(1) Porcentaje de días de precipitación.

(2) Porcentaje de precipitación total. 
atlánticas, por lo que los resultados descienden en Navarra Media (Olite) y más todavía en la Ribera (Carcastillo y Fitero).

La estación invernal es la más propicia a una mayor efectividad pluviométrica con circulación del Noroeste, seguida de primavera. En Navarra Húmeda y Pirineos también en verano registra altos valores. En Navarra Media y Ribera en el verano y en el otoño proporciona bajos registros.

El día 27-11-1983 hubo una situación del NW lluviosa en Navarra. La acentuación de una vaguada que se mueve hacia el SE y se sitúa al Sur de Dinamarca (topografía de $500 \mathrm{mb}$ ) y la retirada de una dorsal hacia el Norte de África, provoca la materialización de una corriente de componente WNW que llega a nuestra área de estudio con un amplio recorrido por el océano. En la topografía de $300 \mathrm{mb}$ la corriente en chorro es del NW en el centro de Francia. En superficie la situación es reflejo de la de altura. En efecto un sistema de borrascas se extiende desde el Oeste de Escocia hasta el Norte de Alemania con centro en el mar del Norte y el anticiclón Atlántico se encuentra en el SW de la Península. Ambos centros de acción dirigen sobre Navarra un flujo del NW, acompañado de un frente solitario que al mediodía atraviesa Navarra (Mapa 1).

Con este tipo de situación en que el centro de la borrasca está alejado, por encima del paralelo $50^{\circ}$, son el Cantábrico Oriental y Navarra Húmeda las regiones españolas que mayor cantidad de lluvia registran. Las masas de aire marítimo polares dan $24 \mathrm{~mm}$ en San Sebastián, y al penetrar en Navarra chocan con las montañas del macizo de Cinco Villas, se estancan y se ven obligadas a ascender aumentando las precipitaciones (Articutza $64 \mathrm{~mm}$ ); nuevas pantallas se oponen al flujo y producen numerosas lluvias (Sumbilla $41 \mathrm{~mm}$, Errazu $44 \mathrm{~mm}$ ). En su trayectoria hacia el Este las montañas cada vez más altas producen nuevos estancamientos que aumentan la cantidad recogida (Roncesvalles $72,8 \mathrm{~mm}$, Valcarlos $46,3 \mathrm{~mm}$ ). Hacia el Este se producen nuevos frenos con relieves más elevados, pero las precipitaciones disminuyen (Esparza de Salazar $14,5 \mathrm{~mm}$ y Urzainqui $25 \mathrm{~mm}$ ). Las lluvias descienden hacia el Sur y Este, si bien siguen siendo elevadas en los observatorios bien expuestos (Alsasua $32,4 \mathrm{~mm}$, Noain $12,4 \mathrm{~mm}$ ) y en las montañas de las Sierras Exteriores (Goñi $40,7 \mathrm{~mm}$ ). Al sur de estas, en Navarra Media y Ribera, los valores descienden (Alloz $8 \mathrm{~mm}$, Fitero lp.).

En el Norte de Navarra el cielo estuvo totalmente cubierto; humedad relativa alta; nieblas y visibilidad escasa; viento de tercer cuadrante rolando al NW, atemporalado, con rachas de huracanado; llueve todo el 
Mapa n. 1.-Situación del NW. 27-11-1983.

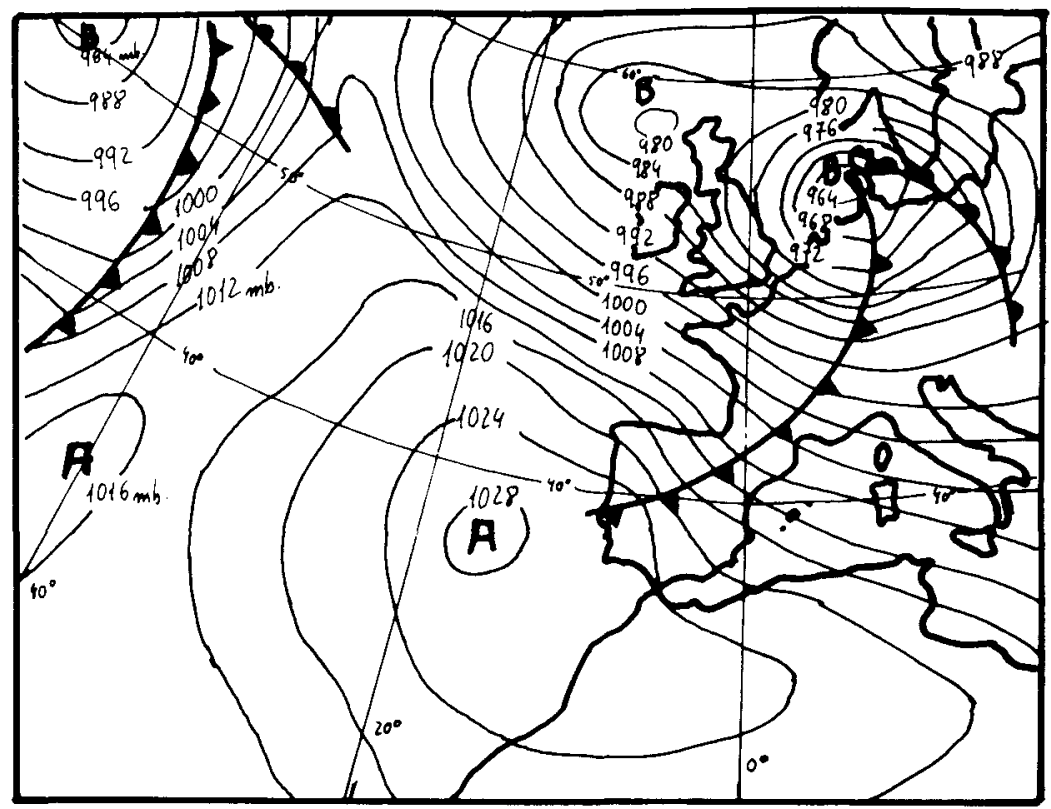

12 h.-Superficie.

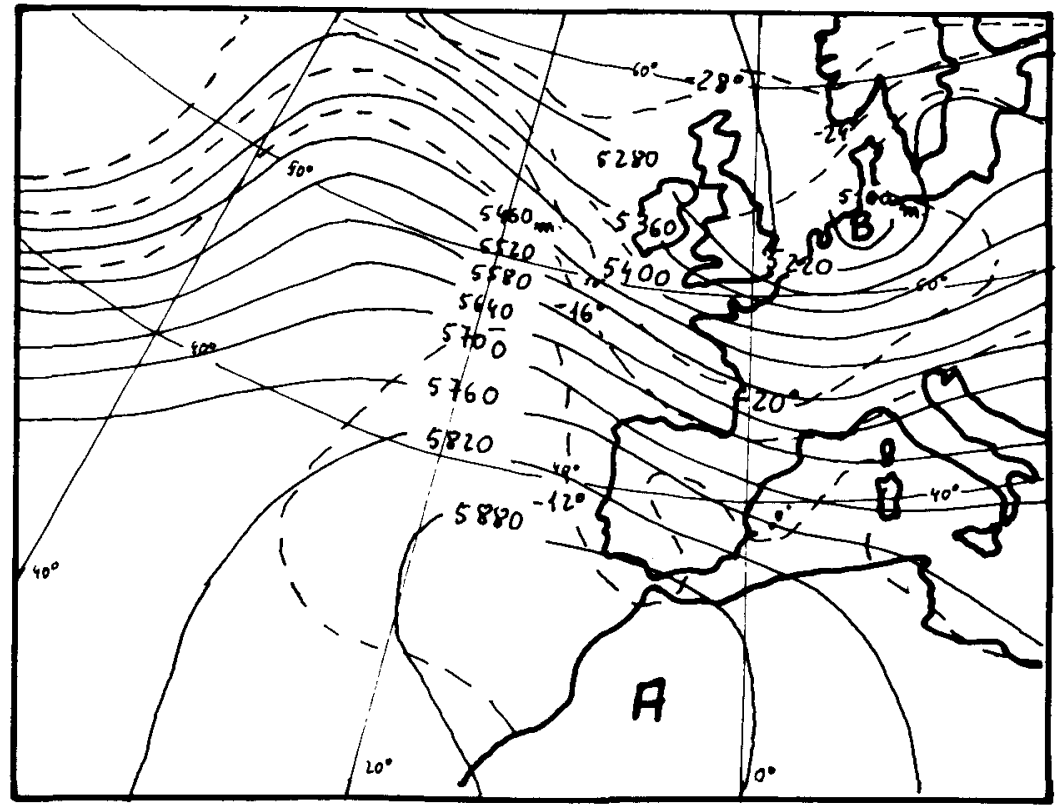

12h. $-500 m b$. 
día. En la Cuenca de Pamplona cielo cubierto de cúmulos y estratocúmulos; humedad relativa alta; viento, brisa moderada del SSW rolando a brisa fuerte del NW; descenso acusado de presión. En el Sur de Navarra cielo nuboso a cubierto con cúmulos y estratocúmulos; humedad relativa inferior; viento encalmado y fuerte del NW posteriormente; lloviznas.

\section{SITUACIÓN DEL NORTE (N)}

Pese a la escasa frecuencia anual de este tipo de circulación, los días de lluvia que proporciona son numerosos y todavía más la cantidad aportada en Navarra. Esto se explica por la dificultad existente para que se materialice la circulación meridiana, más frecuente en invierno y primavera, cuando el aire frío de latitudes polares se refuerza e invade nuestra área de estudio; esto suele suceder cuando la dorsal atlántica de bloqueo se prolonga hasta altas latitudes y un embolsamiento frío se sitúa en el Centro o Sur de Europa; ambos centros de acción dirigen una corriente de trayectoria más o menos marina, inestable al recalentarse por su base y si es rápida, conserva las características originales.

Es preciso recordar la situación propicia del Cantábrico Oriental y Navarra a esta advección, pues es normalmente por esta zona por donde penetran. Sin duda, el papel del relieve es fundamental en las precipitaciones; los montes de Navarra Húmeda, los Pirineos, La Cadena Divisoria y finalmente las Sierras Exteriores van a acentuar la inestabilidad y actuar como auténticos murallones, opuestos a esta circulación que producen estancamiento, ascensión y fuertes precipitaciones.

Los valores aportados por esta situación son inferiores a los del NW en relación con la frecuencia de situación. En casi toda Navarra proporcionan porcentajes próximos o superiores al 10 por 100 del total de días de precipitación. Con respecto a la cantidad recogida es también elevada en relación con los días de lluvia. Navarra Húmeda y el Corredor del Araquil son las zonas mejor expuestas a este flujo. En los Pirineos (sobre todo en los Orientales) se deja sentir el efecto pantalla de estos montes opuestos al flujo meridiano. Tanto la Cadena Divisoria como las Sierras Exteriores se oponen a esta circulación de tal manera que la aportación desciende hacia el Sur, siendo inferior en Navarra Media y Ribera, en donde no llega al 10 por 100 del total aportado. En definitiva, se puede afirmar que las situaciones del Norte dan altas lluvias en toda Navarra. Invierno, es la estación más propicia en toda la Comunidad, seguidas de las estaciones equinociales. En verano tiene muy poca intensidad, sobre todo en Navarra Media y Ribera (Cuadro III). 
CUADRO III. PORCENTAJE DE DÍAS DE PRECIPITACIÓN Y DE PRECIPITACIÓN TOTAL QUE APORTA LA SITUACIÓN N

(1983-1986)

\begin{tabular}{|c|c|c|c|c|c|c|c|c|c|c|}
\hline \multirow{2}{*}{ OBSERVATORIOS } & \multicolumn{2}{|c|}{ PRIMAVERA } & \multicolumn{2}{|c|}{ VERANO } & \multicolumn{2}{|c|}{ OTOÑO } & \multicolumn{2}{|c|}{ INVIERNO } & \multicolumn{2}{|c|}{ ANUAL } \\
\hline & (1) & (2) & (1) & (2) & (1) & (2) & (1) & (2) & (1) & (2) \\
\hline 1. Articutza & 8,4 & 21,7 & 10,9 & 14,7 & 9,4 & 18,7 & 16,3 & 20,1 & 11,3 & 18,8 \\
\hline 2. Sumbilla & 9,3 & 19 & 13,5 & 9,4 & 9,9 & 20,1 & 15,5 & 23.8 & 12,1 & 18,1 \\
\hline 3. Eugui-Esteribar & 7,6 & 17,6 & 13 & 6.6 & 8,7 & 15,4 & 14,7 & 23,5 & 11 & 15,8 \\
\hline 4. Abaurrea Alta & 7,3 & 12,4 & 10,6 & 5,6 & 10,2 & 12,2 & 15,4 & 16,6 & 10,9 & 11,7 \\
\hline 5. Alsasua & 9,2 & 20,2 & 15,6 & 5,5 & 9,7 & 18 & 15.7 & 28,6 & 12,6 & 18,1 \\
\hline 6. Pamplona-Noain & 8,1 & 15,1 & 10,2 & 3,7 & 10,2 & 10,3 & 17,6 & 33,4 & 11,6 & 15,6 \\
\hline 7. Yesa .......... & 10,1 & 11,5 & 3,4 & 0.7 & 9,1 & 9,2 & 15,5 & 25,6 & 9,5 & 11,7 \\
\hline 8. Olite & 11,6 & 6,1 & 3,2 & 0,6 & 10,5 & 4,2 & 17 & 26,4 & 10,6 & 9,3 \\
\hline 9. Carcastillo & 9,8 & 6,9 & - & - & 8,9 & 5,2 & 17,7 & 21,8 & 9 & 8,5 \\
\hline 10. Fitero & 7,3 & 5,5 & 4,1 & 1,3 & 8,9 & 8,9 & 21 & 14,8 & 10,3 & 7,6 \\
\hline
\end{tabular}

(1) Porcentaje de días de precipitación.

(2) Porcentaje de precipitación total.

El día 6-2-83 hubo circulación del Norte; la corriente en chorro es lenta y ondulada con un anticiclón Atlántico de bloqueo que se extiende meridianamente por encima del paralelo $60^{\circ}$; simultáneamente un embolsamiento frío centrado en el Norte de Alemania se mueve hacia el Sur y ocupa Europa Central. Ambos centros de acción dirigen sobre la Península una corriente rápida del $\mathrm{N}$ con ramal de la corriente en chorro del mismo componente, que el día seis rodea al embolsamiento en las proximidades de los Pirineos y el día siete invade la Península. En superficie la situación es muy parecida. La borrasca es muy potente y ejerce su radio de acción desde Europa Nórdica al Mediterráneo (Mapa 2).

La circulación meridiana que llega a Navarra produce chubascos de tormenta en forma de nieve, debido a la inestabilidad producida por las masas de aire de trayectoria maritima. La buena posición de Navarra, entre el anticiclón Atlántico y la borrasca que se sitúa en Europa Central, favorece la presencia de precipitaciones intensas. El cielo se cubre de estratos y estratocúmulos y los vientos aumentan hacia el Sur, siendo fuertes de componente WNW o NW.

Los focos lluviosos se registran en los observatorios de "la Montaña Navarra", más expuestos a la advección meridiana. Destacan por la cantidad recogida, próxima o superior a $70 \mathrm{~mm}$, los observatorios de la Cuenca del Bidasoa y de los Pirineos Centrales, situados junto a autén- 
Mapa n. ${ }^{\circ}$ 2.-Situación del N. 6-2-1983.

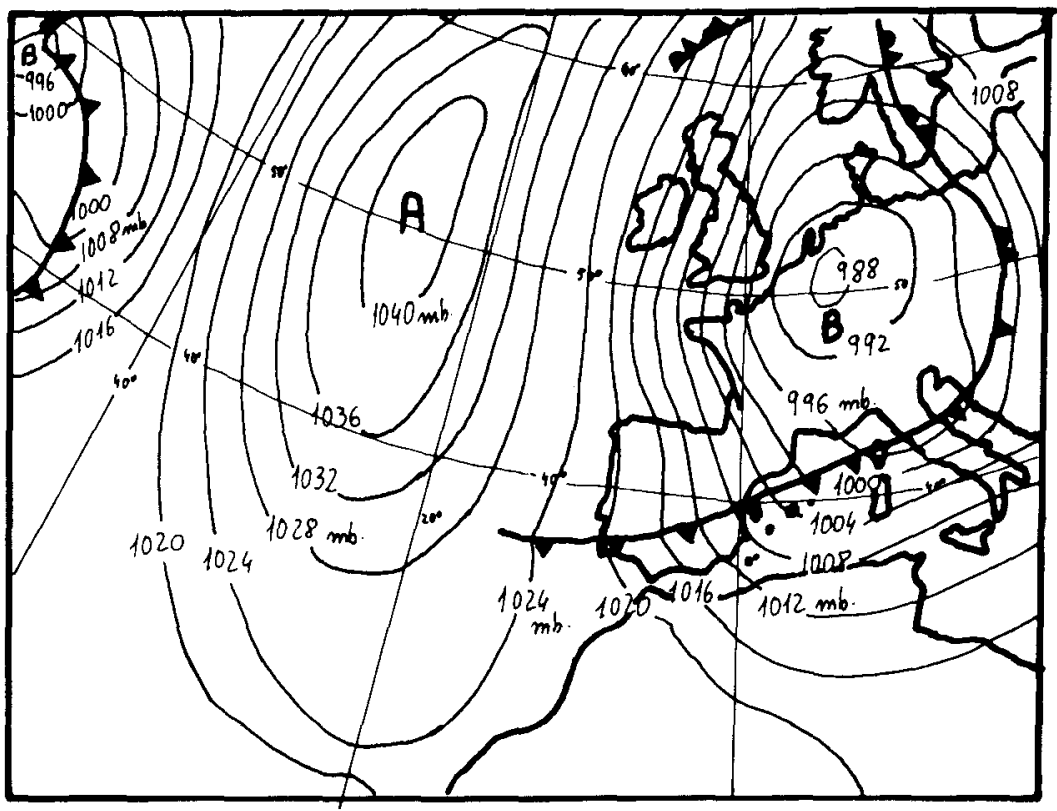

12 h.-Superficie.

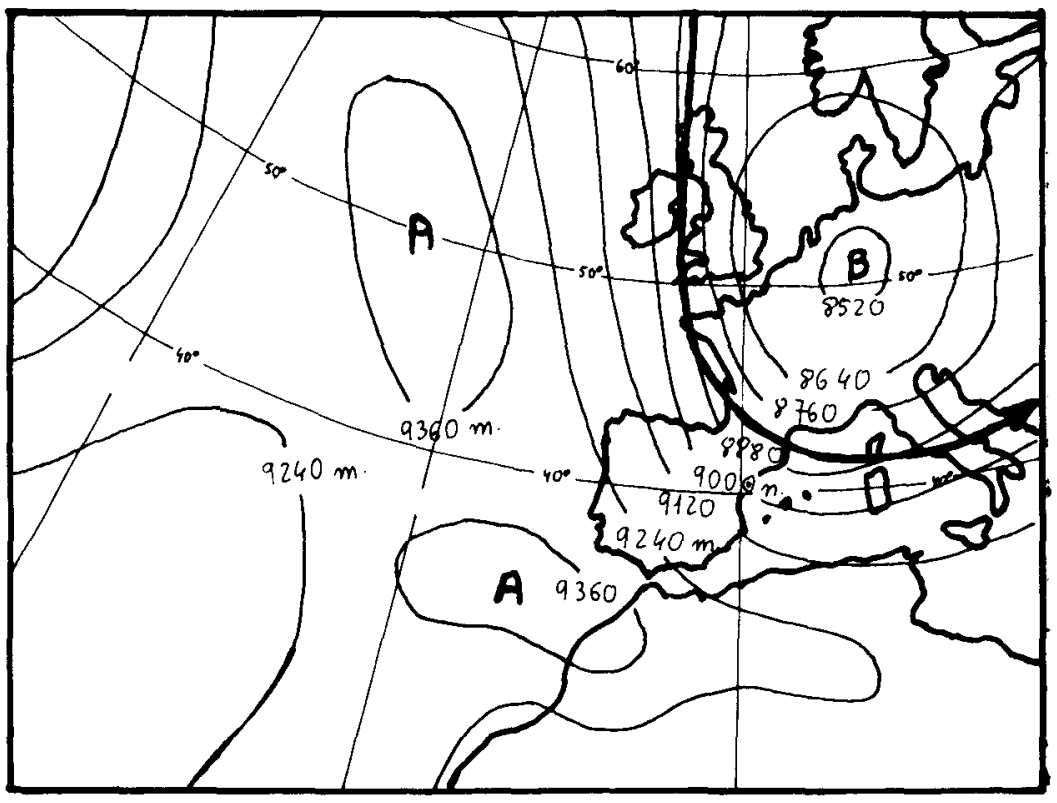

12 h. $-300 \mathrm{mb}$. 
ticas pantallas de humedad (Roncesvalles $69,5 \mathrm{~mm}$, Sumbilla $71,8 \mathrm{~mm}$ ). El resto de Navarra Húmeda y Pirineos anota también cantidades importantes de precipitación por encima de los $40 \mathrm{~mm}$. En las Cuencas Intermedias, al Sur de la Cadena Divisoria, la cantidad recogida es algo inferior, si bien depende este hecho de los diversos subsectores; así algunos lugares del Corredor del Araquil son tan lluviosos como los Pirineos y el Valle de Goñi, que supone un nuevo ascenso de las masas de aire y registra más de $50 \mathrm{~mm}$ de precipitación; sin embargo la cantidad recogida desciende en la Cuenca de Pamplona, aunque se superan los $20 \mathrm{~mm}$ de precipitación. Es decir la Cadena Divisoria, cuando las advecciones del Norte son rápidas e inestables y la corriente en chorro se sitúa próxima a Navarra, no supone una pantalla muy efectiva. Finalmente Navarra Media y Ribera registran las precipitaciones más bajas por su posición meridional con respecto a las Sierras Exteriores.

\section{SITUACIÓN DEL NORDESTE (NE)}

Tiene lugar cuando la dorsal del Atlántico con orientación NE-SW, se extiende hasta Escandinavia y una colada fría se sitúa en Europa Central; entre ambos centros de acción circulan masas de aire muy frías, según la época del año, acompañadas a veces de frentes fríos. Se trata de viejas perturbaciones procedentes del Atlántico que han recorrido el continente (Pedelaborde, 1970, 114 y Estienne-Godard, 1970, 177).

Este tipo de situaciones son poco importantes a la hora de dar días de lluvia y con respecto a la precipitación total. Pese a ser este tipo de circulación más frecuente que la del Norte, los valores en cuanto a precipitación son bastante más bajos debido principalmente a que las masas de aire de primer cuadrante son frías y con una trayectoria continental por Europa Central, no puede cargarse de humedad, por lo que las Iluvias, si se producen, son de intensidad ligera o moderada. Solamente Navarra Húmeda, los Pirineos y el Corredor del Araquil pueden recibir lluvias significativas cuando estas situaciones van acompañadas de frentes frios o bien la situación de Navarra es próxima al embolsamiento frí; lo más normal es que den precipitaciones débiles en los Valles Húmedos Occidentales y a veces en la Cuenca del Bidasoa y Pirineos Centrales, produciendo tan solo un aumento de nubosidad en el resto de «la Montaña Navarra".

En Navarra Húmeda, Pirineos Centrales y Corredor del Araquil se registran algo más del cinco por ciento de los días de lluvia; en los Pirineos Orientales y en la Cuenca de Pamplona los valores disminuyen, 
para ser muy bajos en el resto. En cuanto a la cantidad aportada sucede lo mismo; en Navarra Húmeda y en los Pirineos suponen el tres por ciento de la lluvia anual o valores parecidos y en Navarra Media y Ribera no alcanzan el uno por ciento. Es decir, la poca capacidad de lluvia de estas masas de aire queda prácticamente anulada por las Sierras Exteriores (Cuadro IV). Otoño es la estación menos apropiada y primavera, verano e invierno las que más días de lluvia y precipitación aportan, dentro de una tónica de penuria pluviométrica.

El día 9 de febrero de 1983 (Mapa 3) una dorsal de bloqueo se extiende por el Atlántico hasta Escandinavia con orientación SW-NE; simultáneamente una vaguada fría con centro en el SE de Francia y $-36^{\circ}$ de temperatura en la topografía de $500 \mathrm{mb}$, engloba a la Peninsula por su parte Sudoeste; estos dos centros de acción dirigen una corriente del NE preludio de la ola de frío de febrero de 1983. En la topografía de 300 $\mathrm{mb}$ la corriente en chorro muy ondulada es del NE en el Oeste de Galicia y del WSW en el Norte de África. En superficie la circulación es débil del NE.

Navarra Húmeda es la que más cantidad recoge (Articutza $8,9 \mathrm{~mm}$, Errazu $10 \mathrm{~mm}$,) los Pirineos actúan de freno a la débil inestabilidad existente por lo que las precipitaciones son moderadas en los Pirineos Centrales y nulas en la parte oriental (Roncesvalles $5,5 \mathrm{~mm}$, Urzainqui -). En

CUADRO IV. PORCENTAJE DE DÍAS DE PRECIPITACIÓN Y DE PRECIPITACIÓN TOTAL QUE APORTA LA SITUACIONN NE (1983-1986)

\begin{tabular}{|c|c|c|c|c|c|c|c|c|c|c|}
\hline \multirow{2}{*}{ OBSERVATORIOS } & \multicolumn{2}{|c|}{ PRIMAVERA } & \multicolumn{2}{|c|}{ VERANO } & \multicolumn{2}{|c|}{ OTOÑO } & \multicolumn{2}{|c|}{ INVIERNO } & \multicolumn{2}{|c|}{ ANUAL } \\
\hline & (1) & (2) & (1) & (2) & (1) & (2) & $(1)$ & (2) & (1) & (2) \\
\hline 1. Articutza & 8,4 & 3,5 & 5,4 & 3,7 & 2 & 1,2 & 4,9 & 2,2 & 5,2 & 2,7 \\
\hline 2. Sumbilla & 7,4 & 3,6 & 7,1 & 5 & 2,3 & 0,7 & 5,3 & 2,3 & 5,5 & 2,9 \\
\hline 3. Eugui-Esteribar & 7,6 & 3,6 & 8,1 & 4,2 & 1,2 & 0,5 & 5 & 1,4 & 5,5 & 2,4 \\
\hline 4. Abaurrea Alta . & 3,4 & 1,3 & 8,2 & 6,5 & 0,8 & 0,3 & 3,8 & 2,2 & 4,1 & 2,6 \\
\hline 5. Alsasua & 8,2 & 4,9 & 5,2 & 2,4 & 2,4 & 1,3 & 5,4 & 3,8 & 5,6 & 3,1 \\
\hline 6. Pamplona-Noain & 5,1 & 1,6 & 5,1 & 0,7 & 0,8 & 0,1 & 2,8 & 1,4 & 3,5 & 1 \\
\hline 7. Yesa & 1,6 & 0,1 & 1,7 & 0,7 & - & - & 1,5 & 0,7 & 1,2 & 0,4 \\
\hline 8. Olite & 2,3 & 0,7 & 1,6 & 0,1 & - & - & 1,5 & 0,1 & 1,3 & 0,2 \\
\hline 9. Carcastillo & 1,8 & 1 & - & 一 & - & - & 一 & - & 0,4 & 0,2 \\
\hline 10. Fitero $\ldots \ldots$ & 2,7 & 0,9 & 4,1 & 0,1 & - & - & 4,2 & 0,7 & 2,8 & 0,4 \\
\hline
\end{tabular}

(1) Porcentaje de dias de precipitación.

(2) Porcentaje de precipitación total. 
Mapa n. ${ }^{\circ}$ 3.-Situación del NE. 9-2-1983.

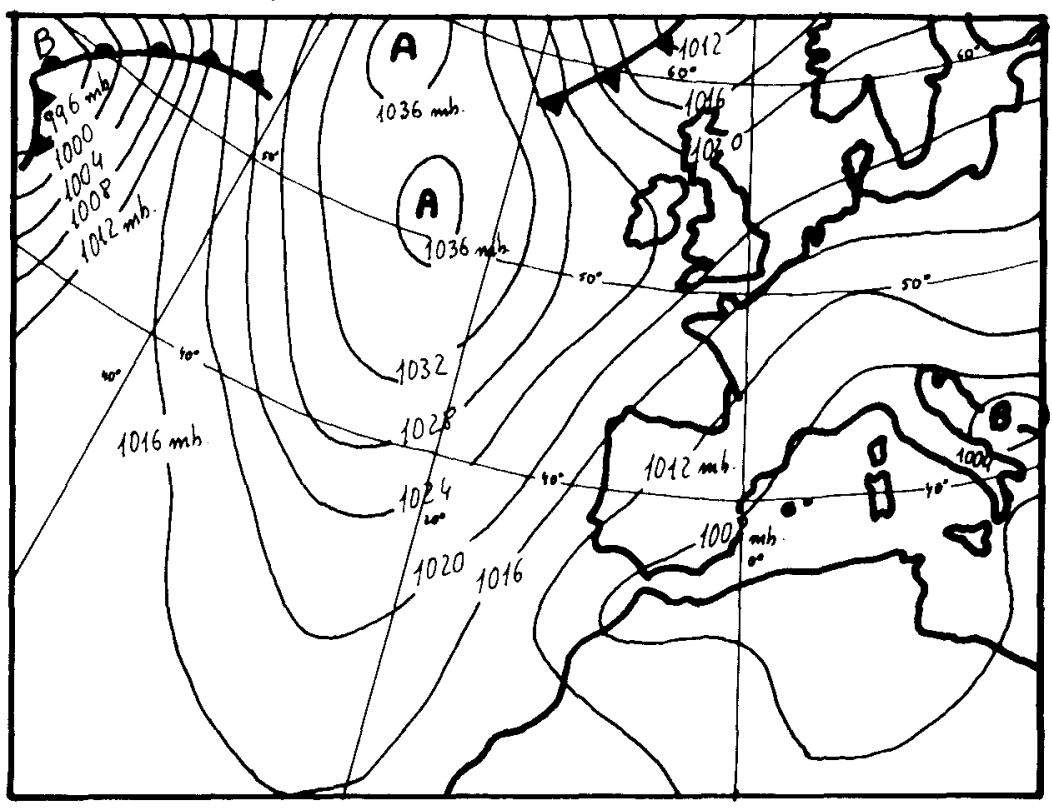

12h.-Superficie.

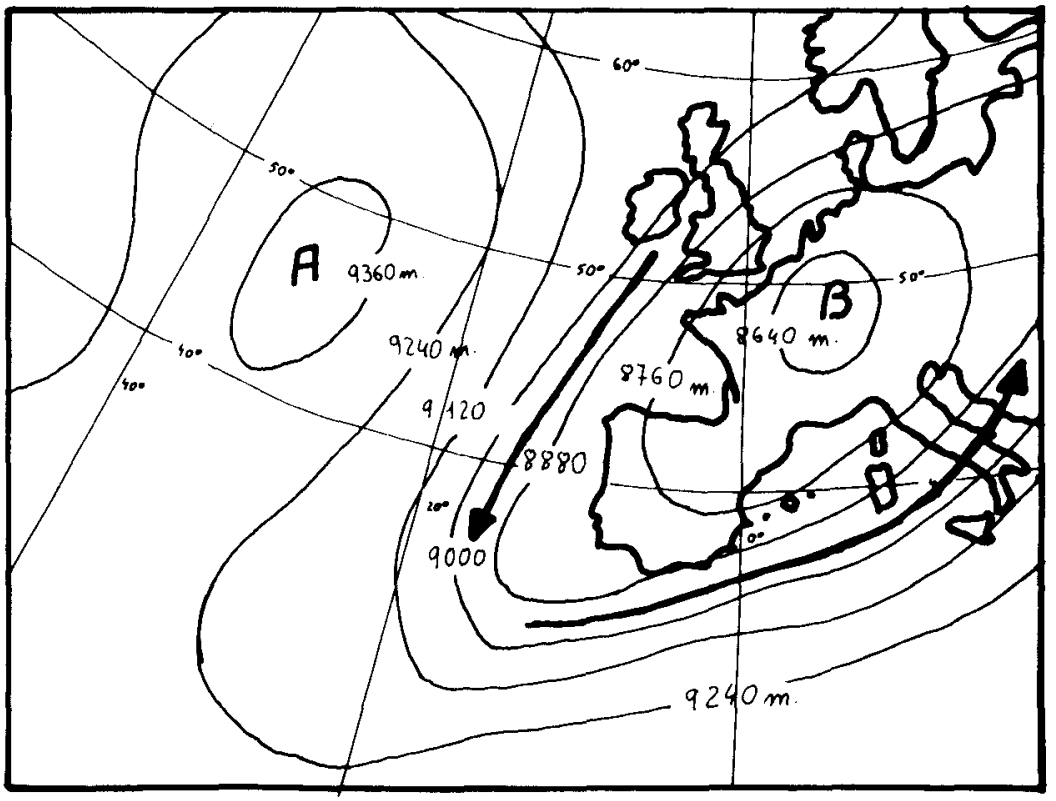

12 h. $-300 \mathrm{mb}$. 
las Cuencas Intermedias existen diferencias entre las abiertas al flujo oceánico (Alsasua $9,5 \mathrm{~mm}$ ) y las más orientales (Pamplona $0,8 \mathrm{~mm}$ ). Navarra Media, a pesar de su situación a sotavento de las Sierras Exteriores, obtiene lluvia ligera (Alloz $2 \mathrm{~mm}$ ). En la Ribera no llueve normalmente y donde lo hace es lluvia ligera (Fitero $0,3 \mathrm{~mm}$ ).

En el Norte de Navarra el cielo está cubierto de nubes medias, altostratos, que se transforman en cúmulos y estratos por la tarde; el viento es débil y moderado del $\mathrm{N}$ y NNW. En la cuenca de Pamplona cielo poco nuboso con predominio de nubes de altura media, altocúmulos, y bajas, estratocúmulos; viento en calma, ligero o moderado del NNW; las precipitaciones en ambas zonas son en forma de nieve. En el Sur de Navarra cielo despejado y brisa fuerte del NNW.

\section{SITUACIÓN DEL ESTE/SUDESTE (E/SE)}

En nuestros años de estudio no se ha observado una presencia importante de este tipo de circulación. En algunas ocasiones el flujo del Este se debe principalmente a la presencia de un anticiclón en Europa Central que formaliza sobre la Península un flujo de Levante; este tipo de situaciones, que se dan en todas las estaciones del año, no producen normalmente precipitaciones en Navarra. Por el contrario, cuando el aire polar frío en una circulación ondulada se profundiza por el Atlántico Sur y forma una depresión que se desplaza hacia el Mediterráneo, en donde entran en contacto el aire frío Atlántico con el cálido Mediterráneo, se origina una situación Sudeste que da importantes precipitaciones en el interior según su potencia y desplazamiento puede afectar a Navarra. Un último y más importante esquema isobárico se puede citar y que más afecta a nuestras comarcas; cuando la circulación es excesivamente ondulada la dorsal del Atlántico se desplaza hacia Europa Central y una colada fría se ubica sobre la Península o al Oeste de ella, la cual atrae aire cálido mediterráneo que, al entrar en contacto con el frío de la vaguada, origina precipitaciones. Sin embargo es preciso afirmar que algunas de estas situaciones, por existir depresiones en superficie y bajas frias en altura, se han clasificado dentro del grupo de bajas frías, por lo que la frecuencia de las situaciones del Sudeste es inferior en nuestro estudio.

Este tipo de situaciones, por su procedencia meridional, afectan más a la Depresión del Ebro, destacando algunos puntos de la Ribera Navarra, que alcanzan los mayores procentajes de dias de lluvia y total reco- 
gido. Datos inferiores se consiguen en la Cuenca de Pamplona y Navarra Media. Los valores van disminuyendo conforme los observatorios se sitúan en una posición más septentrional, en los Pirineos y en el Corredor del Araquil y todavía más en los valles húmedos del Norte de Navarra. Es decir, ocurre lo contrario que con las anteriores situaciones: Navarra Media y Ribera son más afectadas que "la Montaña Navarra» (Cuadro V).

Otoño es la estación más propicia a flujos lluviosos del Sudeste; así en Fitero se recoge más del diez por ciento de la precipitación total. En segundo lugar y con bastante diferencia figuran primavera y verano, esta última no en todos los observatorios. En invierno no se da.

Se ha clasificado el día 6-11-83 como de circulación del E/SE. El primer día de noviembre la circulación zonal estaba alejada de nuestras latitudes y una baja fría extensa se situaba al Oeste de Lisboa. En días posteriores una vaguada atlántica la desplazó al NNE, pasando al Norte de África. El día 6 en el mapa de 500 milibares se observan unos mínimos de presión centrados al Oeste de la Península y en el Norte de África, que se aproximan por el Atlántico, y una profunda vaguada que se orienta junto al meridiano $30^{\circ}$. Las gotas frías de altura tienen reflejo en superficie, situándose dos mínimos de presión, uno al Sudoeste de la

\section{CUADRO V. PORCENTAJE DE DÍAS DE PRECIPITACIÓN Y DE PRECIPITACIÓN TOTAL QUE APORTA LA SITUACIÓN E/SE} (1983-1986)

\begin{tabular}{|c|c|c|c|c|c|c|c|c|c|c|}
\hline \multirow{2}{*}{ OBSERVATORIOS } & \multicolumn{2}{|c|}{ PRIMAVERA } & \multicolumn{2}{|c|}{ VERANo } & \multicolumn{2}{|c|}{ OTOÑO } & \multicolumn{2}{|c|}{ INVIERNO } & \multicolumn{2}{|c|}{ ANUAL } \\
\hline & (1) & (2) & (1) & (2) & (1) & (2) & (1) & (2) & (1) & (2) \\
\hline 1. Articutza & 1,3 & 1,6 & 0,6 & 0,1 & 4,7 & 1,6 & - & - & 1,7 & 0,8 \\
\hline 2. Sumbilla & 1 & 2,5 & 0,8 & 0,1 & 3,8 & 1,4 & - & - & 1,4 & 1 \\
\hline 3. Eugui-Esteribar & 1,3 & 2,5 & 0,8 & 0,2 & 3,7 & 3,5 & - & - & 1,3 & 1,5 \\
\hline 4. Abaurrea Alta . & 1,7 & 2,1 & 2,3 & 0,8 & 5,9 & 3,2 & - & - & 2,5 & 1,5 \\
\hline 5. Alsasua & 1 & 3,1 & - & - & 5,6 & 4,1 & - & - & 1.7 & 1,8 \\
\hline 6. Pamplona-Noain & 1,7 & 3,6 & - & - & 6 & 4,2 & - & - & 1,9 & 3,9 \\
\hline 7. Yesa ........ & 1,6 & 7,4 & 1,7 & 0,3 & 6,8 & 4,3 & - & - & 2,5 & 3 \\
\hline 8. Olite & 1,6 & 4,7 & 3,3 & 3,3 & 5,8 & 4,8 & - & - & 2,6 & 3,2 \\
\hline 9. Carcastillo & 1,8 & 5,8 & 4,2 & 0,5 & 7,6 & 9,6 & - & - & 3,4 & 4 \\
\hline 10. Fitero & 1,8 & 6,2 & 6,1 & 6,9 & 7,6 & 12,5 & - & - & 3,9 & 6,4 \\
\hline
\end{tabular}

(1) Porcentaje de dias de precipitación.

(2) Porcentaje de precipitación total. 
Península y el otro en la mar Menor, mandando este último un flujo del SE sobre la Península (Mapa 4).

La inestabilidad en altura y llegada de masas de aire del Mediterráneo provocan fuertes chubascos tormentosos en la región valenciana y catalana, que llegan a la Depresión del Ebro con una menor efectividad. En Navarra originan precipitaciones en la Ribera (Carcastillo $34,5 \mathrm{~mm}$ ), descienden en Navarra Media (Olite $13 \mathrm{~mm}$ ) y después de remontar las Sierras Exteriores las masas de aire sufren nuevos ascensos en los Pirineos (Eugui $16,8 \mathrm{~mm}$ ). En el norte de Navarra y en zonas mal orientadas a este flujo las precipitaciones decrecen considerablemente (Alsua $0,4 \mathrm{~mm}$, Articutza $0,8 \mathrm{~mm}$ ).

En el Norte de Navarra cielo nuboso a cubierto; humedad relativa baja; visibilidad alta; descenso de presión diurno; brisa moderada a fuerte del S y del SSE; llueve ligeramente a la tarde con viento S. En la Cuenca de Pamplona cielo cubierto de cúmulos y de estratocúmulos; visibilidad baja, calimas; viento en calma o brisa moderada del $\mathrm{S}$; descenso de presión; llueve a la tarde y a la noche con la aproximación de la vaguada. En el sur de Navarra cielo cubierto de estratos, cúmulos y estratocúmulos; humedad relativa alta; visibilidad escasa; brisa moderada del ESE; llueve todo el dia.

\section{SITUACIÓN DEL SUR/SUDOESTE (S/SW)}

A lo largo del año y principalmente durante las estaciones equinociales es frecuente observar en altura una circulación ondulada que da lugar a la profundización de vaguadas por el Atlántico hasta latitudes más 0 menos meridionales. Estas coladas frías formalizan sobre la Península masas de aire de retorno, que debido a su largo recorrido por el océano se han calentado y cargado de humedad. Al penetrar en el Península y atravesarla chocan con los principales relieves montañosos y cuando llegan a Navarra no tienen tanta efectividad, e incluso algunas veces, si la trayectoria es más occidental, no nos afectan.

Por ser una masa de aire de procedencia meridional afecta principalmente a Navarra Media y Ribera en donde proporciona aproximadamente el 15 por 100 de los días de precipitación y una contribución similar al total de lluvias. En estas comarcas la contribución al total de lluvias es superior que con las situaciones del Noroeste y sólo se ven superadas por las bajas frias. 
Mapa n. ${ }^{4}$.-Situación del E/SE. 6-11-1983.

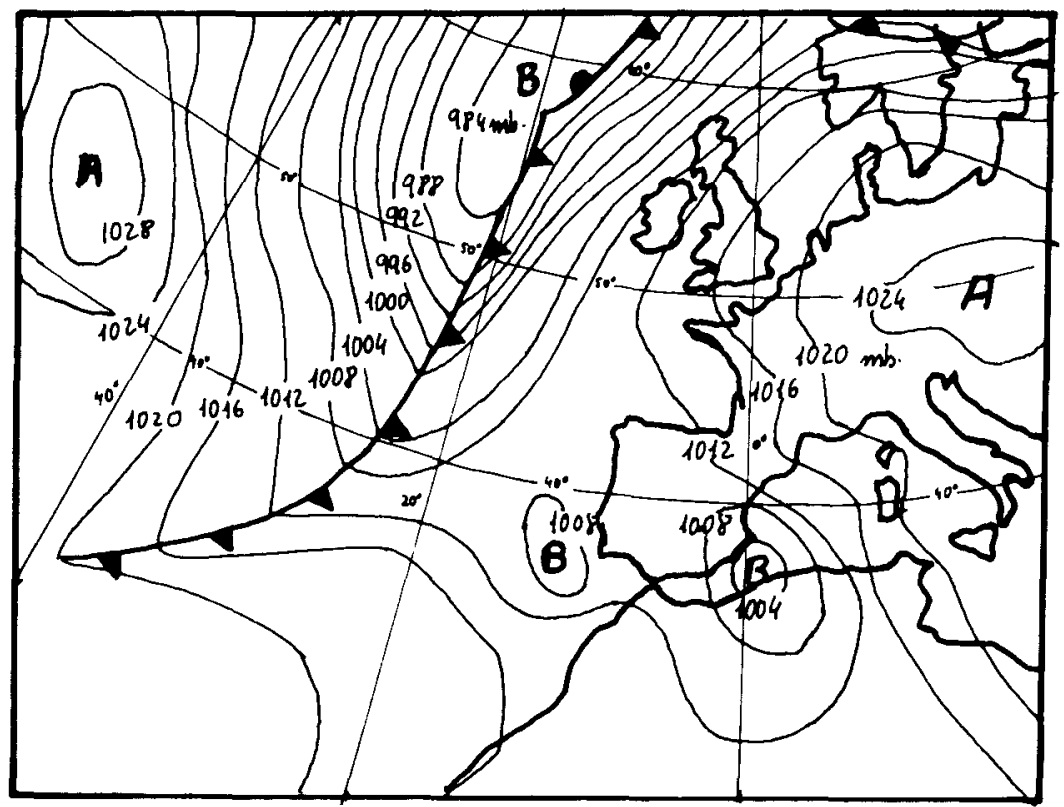

12 h.-Superficie.

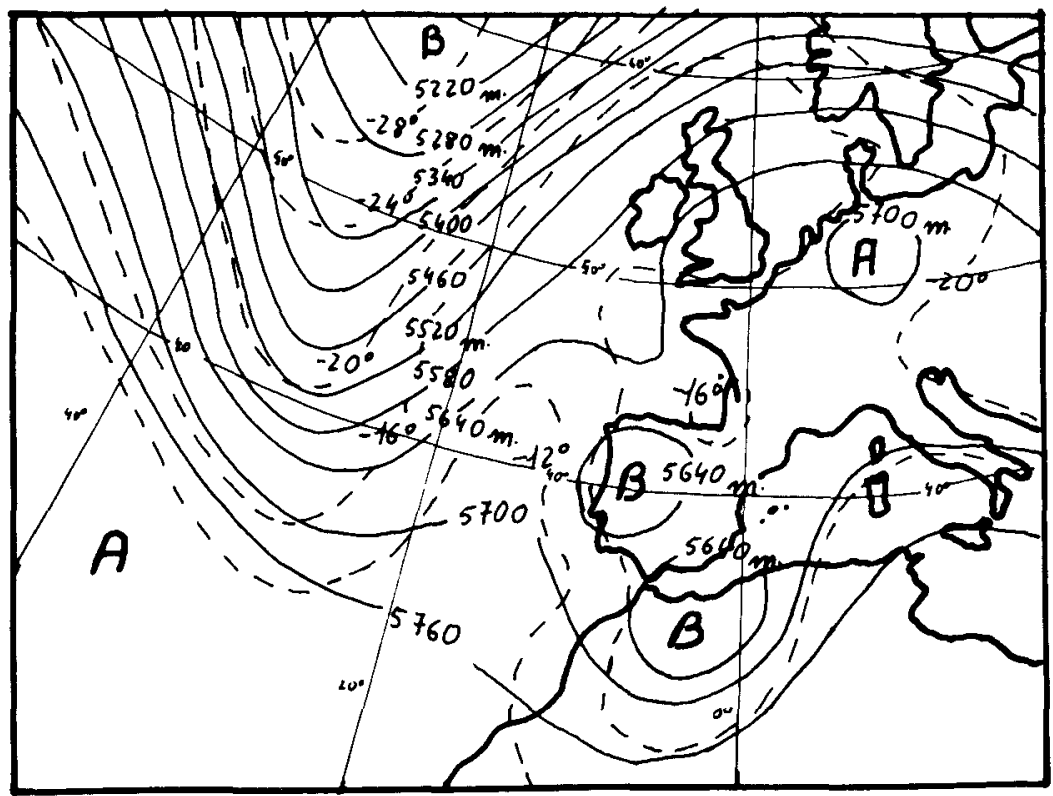

$12 \mathrm{~h} .-500 \mathrm{mb}$. 
Los observatorios pirenaicos presentan también altos valores, especialmente los Pirineos Orientales. Es notoria la diferencia de los Pirineos Orientales con respecto al Corredor del Araguil y a los Pirineos Centrales. Navarra Húmeda, opuesta a este flujo, presenta los valores más bajos (Cuadro IV).

De los datos analizados se desprende que las masas de aire de tercer cuadrante penetran en la parte meridional de Navarra originando precipitaciones en Navarra Media se ven obligadas a un nuevo ascenso provocado por las Sierras Exteriores. Asi los observatorios de Navarra Media, situados en este caso a barlovento son bastante irrigados. Posteriormente y una vez atravesadas las Cuencas Intermedias son obligadas a un nuevo ascenso para traspasar los Pirineos, más pronunciado en la parte Oriental que en el Occidente. Finalmente Navarra Húmeda se encuentra a sotavento de la Cadena Divisoria, por lo que los resultados pluviométricos son inferiores.

Otoño es la estación del año de más afectividad pluviométrica con situaciones del Sudoeste, debido al poder de la transición al invierno como generadora de corrientes onduladas que originan vaguadas atlánticas responsables de estas advecciones; primavera e invierno figuran a continuación, estando casi ausentes en verano.

CUADRO VI. PORCENTAJE DE DÍAS DE PRECIPITACIÓN Y DE PRECIPITACIÓN TOTAL QUE APORTA LA SITUACIÓN S/SW (1983-1986)

\begin{tabular}{|c|c|c|c|c|c|c|c|c|c|c|}
\hline \multirow{2}{*}{ OBSERVATORIOS } & \multicolumn{2}{|c|}{ PRIMAVERA } & \multicolumn{2}{|c|}{ VERANO } & \multicolumn{2}{|c|}{ OTOÑO } & \multicolumn{2}{|c|}{ INVIERNO } & \multicolumn{2}{|c|}{ ANUAL } \\
\hline & (1) & (2) & (1) & (2) & (1) & (2) & (1) & (2) & (1) & (2) \\
\hline 1. Articutza & 9,3 & 4,9 & 6 & 2,3 & 11,5 & 11,3 & 10,4 & 3 & 9,3 & 5,3 \\
\hline 2. Sumbilla & 10,3 & 7,6 & 3,2 & 1,8 & 14,5 & 14,5 & 9,6 & 2,9 & 9,4 & 6,7 \\
\hline 3. Eugui-Esteribar ... & 10,2 & 9,5 & 4,1 & 5,9 & 14,4 & 21,9 & 13,8 & 7,5 & 10,6 & 11,2 \\
\hline 4. Abaurrea Alta .... & 12,3 & 15,8 & 3,5 & 8 & 17,8 & 26,7 & 13,7 & 17,6 & 11,8 & 17,1 \\
\hline 5. Alsasua $\ldots . \ldots \ldots$ & 9,2 & 11,2 & 7,3 & 4,1 & 14,5 & 20 & 12,7 & 7,8 & 10,9 & 10,8 \\
\hline 6. Pamplona-Noain & 12 & 16,9 & 5,1 & 11,8 & 15,4 & 26,8 & 13,6 & 8,7 & 11,5 & 16 \\
\hline 7. Yesa & 11,7 & 10,5 & 5,1 & 8,1 & 17,1 & 26,4 & 20,8 & 15,5 & 13,7 & 15,2 \\
\hline 8. Olite & 18,6 & 24,5 & 6,6 & 4,8 & 20,9 & 34,2 & 17 & 16,3 & 15,8 & 20 \\
\hline 9. Carcastillo & 16,1 & 20,6 & 6,2 & 0,8 & 21,5 & 29,1 & 20,8 & 21,1 & 15,2 & 17,9 \\
\hline 10. Fitero & 16,5 & 19,5 & 8,2 & 1,5 & 22,8 & 26,4 & 18,9 & 18,8 & 16,3 & 16,5 \\
\hline
\end{tabular}

(1) Porcentaje de dias de precipitación.

(2) Porcentaje de precipitación total. 
El 8-11-84 hubo en Navarra una situación del S/SW. En el mapa de $500 \mathrm{mb}$ la circulación está muy ondulada y una vaguada profunda se orienta N-S, se centra al NW de Galicia y alcanza las Canarias. La dorsal mediterránea se encuentra muy desplazada y sobre la Península la vaguada dirige una masa de aire del SSW marítimo polar que, procedente de Terranova, ha seguido dirección NE y ha alcanzado el paralelo $60^{\circ}$, para poner rumbo Sur por el Atlántico hasta las Canarias y contornear y entrar en la Península de tercer cuadrante. Así pues se trata de masas de aire marítimo polar suavizadas en su largo recorrido por el Atlántico y sobre todo con capacidad higrométrica alta. La temperatura sobre nuestra vertical es de $-20^{\circ}$ (Mapa 5).

En la topografía de 300 milibares la circulación se encuentra muy ondulada y hay corriente en chorro fuerte del SW con eje Barco R. (Islas Madera-Gibraltar-Madrid-Burdeos). En superficie, el reflejo de la vaguada en altura viene representado por las bajas presiones que engloban la Península, la mayor parte de Francia y las Islas Británicas; se trata de un sistema complicado de varios mínimos, entre los cuales el que más afecta se sitúa a la altura de Lisboa; frente cálidos y fríos atraviesan la Península.

Las precipitaciones fueron generales en la Península bien orientada a este flujo. En Navarra se produjeron precipitaciones elevadas con vientos del S o del SE. En Navarra Media fueron abundantes, destacando los observatorios próximos a las Sierras Exteriores, lugares de obligada retención y ascenso (Goñi $60,1 \mathrm{~mm}$, Alloz $67,5 \mathrm{~mm}$, Yesa 39) y algo inferiores, sin dejar de ser altas, en la Ribera Navarra (Fitero 21,3 mm). Las Cuencas Intermedias tuvieron también altas lluvias, más altas en la Cuenca de Pamplona. En los Valles Pirenaicos, debido al obligado ascenso de las masas de aire, las precipitaciones fueron las más elevadas de Navarra, con fuertes tormentas (Esparza de Salazar $77 \mathrm{~mm}$, Urzainqui $73 \mathrm{~mm}$ ) sobre todo en las cabeceras de los valles. Los observatorios de Roncesvalles, Valcarlos y Abaurrea Alta, recibieron cantidades inferiores debido a su posición a sotavento de las Sierras de Baigura, Macizo de Arce y de Orzanzurieta. Finalmente en Navarra Húmeda las precipitaciones también fueron elevadas, aunque inferiores (Articutza $35,3 \mathrm{~mm}$, Errazu 28,5 mm).

En el Norte de Navarra cielo cubierto de nubes bajas cúmulos y estratocúmulos; el viento es fuerte con rachas del S, SSW y SSE; chubascos tormentosos a la noche coincidiendo con la formación de mínimos de presión cercanos a nuestras área de estudio y paso de frentes fríos. En la Cuenca de Pamplona cielo cubierto de nubes bajas, cúmulos y estratocúmulos; brisa moderada a fuerte con rachas de viento fuerte del 
Mapa n. 5.-Situación del S/SW. 8-11-1984.

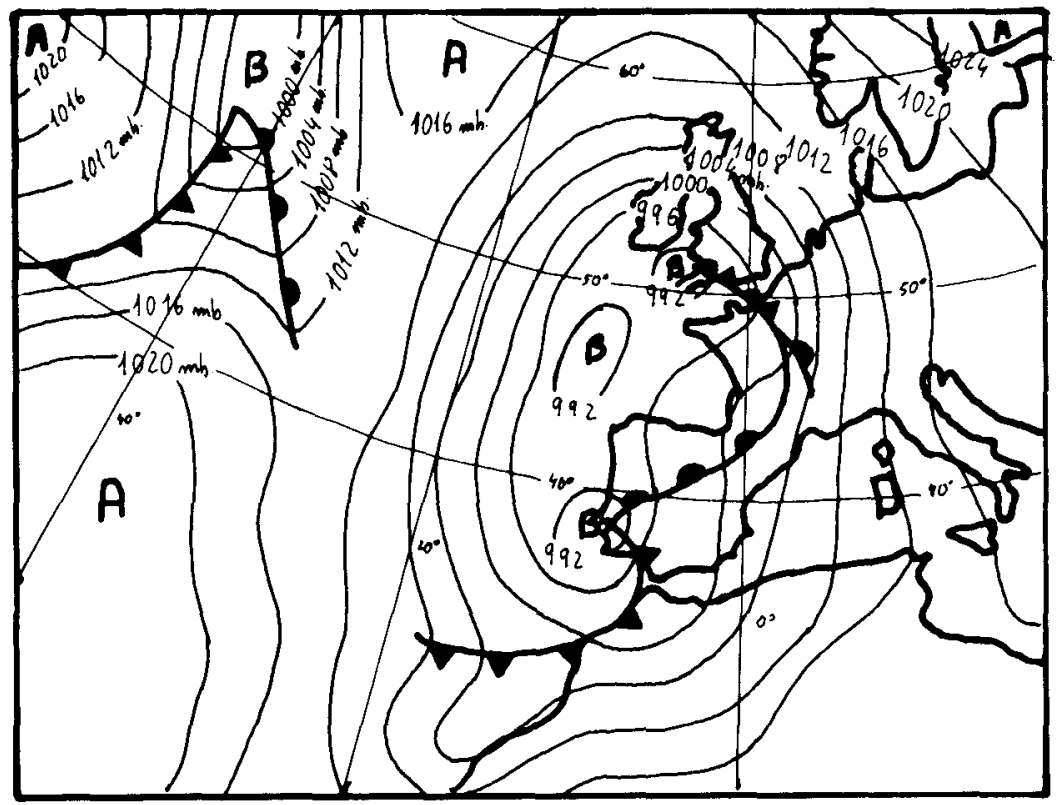

12 h.-Superficie.

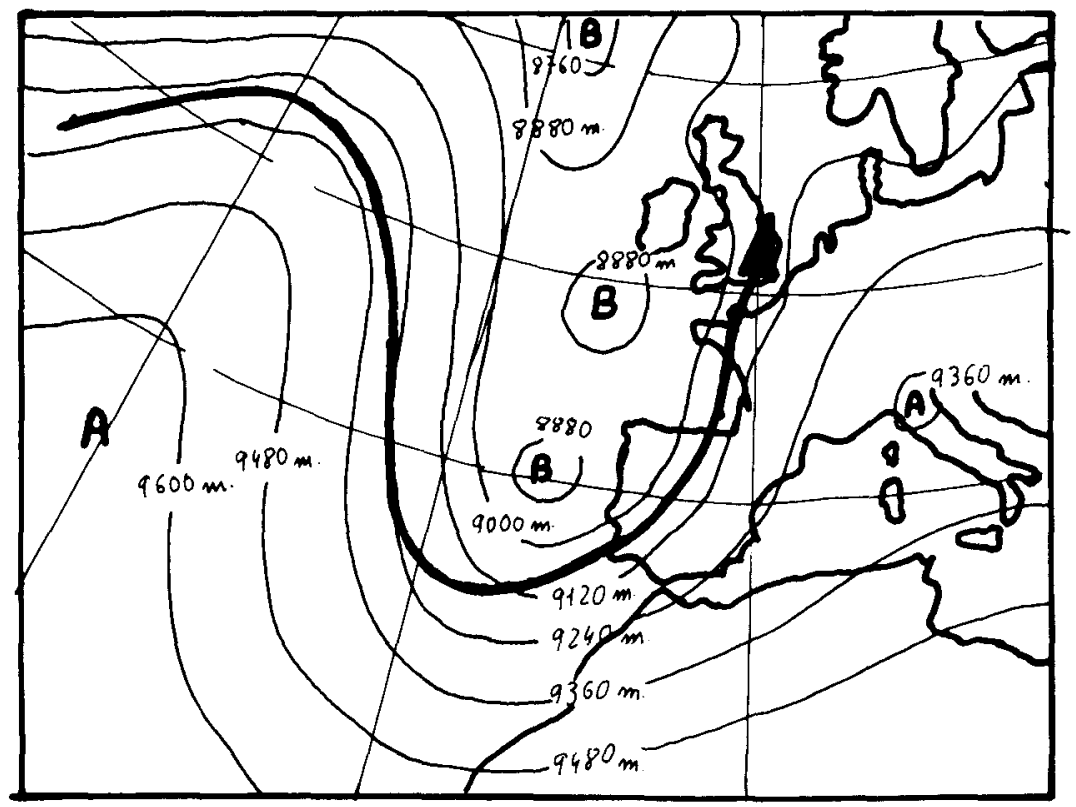

$12 h .-300 \mathrm{mb}$. 
Sur; llueve a la noche con el paso del frente frío. En el Sur de Navarra cielo cubierto de cúmulos y estratocúmulos que alternan con altocúmulos y altostratos; brisa moderada a fuerte de segundo y tercer cuadrante; llueve a la noche con viento fuerte.

\section{SITUACIÓN DEL OESTE (W)}

Se puede afirmar que la situación del Oeste es importante en Navarra en cuanto a los efectos pluviométricos se refiere. En efecto, el descenso de la corriente en chorro y la formación de un pasillo de bajas presiones extendido zonalmente, da lugar a la llegada de masas de aire templadas, de recorrido atlántico, acompañadas de sistemas frontales, cálidos y fríos, que en numerosas ocasiones se traducen en precipitaciones, dependiendo siempre de su fuerza y trayectoria seguida. En general Navarra se encuentra bien situada, sobre todo la parte septentrional.

Pese a la importancia de esta situación es preciso afirmar que normalmente aporta menos precipitaciones que las del Noroeste, debido a que los contrastes térmicos de las masas de aire que generan son menos intensos, $y$ en algunas ocasiones las borrascas llegan envejecidas después de su largo recorrido por el oceáno. Sin embargo a veces conservan su intensidad original y la corriente es rápida y con bastante gradiente isobárico lo que da lugar a lluvias intensas y generales en Navarra.

En toda Navarra proporcionan porcentajes similares de dias de lluvias, entre el 15 y el 20 por 100 , por lo que se trata de una de las situaciones mas lluviosas. Normalmente contribuyen a más del 15 por 100 de las lluvias anuales, salvo en Navarra Húmeda, Pirineos Centrales y Corredor del Araquil, en donde, aun siendo importantes, otros tipos de situaciones (bajas frías y Noroeste) son más efectivas. En cambio en los Pirineos Orientales y Navarra Media aportan cantidades importantes, y también en la Ribera Navarra, si bien son inferiores (Cuadro VII).

Es cierto que la situación latitudinal de Navarra es favorable al flujo del Oeste. Cuando la situación es potente, coincidiendo con corriente en chorro rápidamente sobre nuestra vertical, las lluvias en Navarra pueden ser generales. La estación invernal es la que más precipitación aporta coincidiendo con la posición más meridional de la corriente en chorro. Primavera y otoño resultan también lluviosas con bastante diferencia respecto a verano que arroja porcentajes bajos. 
CUADRO VII. PORCENTAJE DE DÍAS DE PRECIPITACIÓN Y DE PRECIPITACIÓN TOTAL QUE APORTA LA SITUACIÓN W (1983-1986)

\begin{tabular}{|c|c|c|c|c|c|c|c|c|c|c|}
\hline \multirow{2}{*}{ OBSERVATORIOS } & \multicolumn{2}{|c|}{ PRIMAVERA } & \multicolumn{2}{|c|}{ VERANO } & \multicolumn{2}{|c|}{ OTOÑO } & \multicolumn{2}{|c|}{ INVIERNO } & \multicolumn{2}{|c|}{ ANUAL } \\
\hline & (1) & (2) & (1) & (2) & (1) & (2) & (1) & (2) & (1) & (2) \\
\hline 1. Articutza & 20 & 15 & 9,6 & 2,9 & 16,9 & 15,8 & 17,8 & 12,1 & 16,1 & 11,4 \\
\hline 2. Sumbilla & 22,2 & 16,4 & 7,1 & 2,1 & 16,8 & 17,8 & 18,7 & 14,8 & 16,2 & 12,8 \\
\hline 3. Eugui-Esteribar & 22,5 & 16,8 & 7,3 & 2,3 & 17,5 & 20,8 & 18,7 & 16,3 & 16,5 & 14,1 \\
\hline 4. Abaurrea Alta & 23,5 & 26,2 & 9,4 & 13,3 & 20,3 & 25,8 & 22 & 20,5 & 18,8 & 21,4 \\
\hline 5. Alsasua & 22,9 & 15,5 & 7,3 & 3,5 & 22,6 & 21,3 & 17,6 & 16,5 & 17,6 & 14,2 \\
\hline 6. Pamplona-Noain & 21,7 & 18,4 & 10,2 & 3 & 20,5 & 15,9 & 21 & 22,7 & 18,3 & 15 \\
\hline 7. Yesa & 21,9 & 22,6 & 6,8 & 5,4 & 22,7 & 24,4 & 22,5 & 21,5 & 18,5 & 18,5 \\
\hline 8. Olite & 18,6 & 19 & 9,8 & 4,8 & 22,1 & 18,7 & 22,2 & 27,9 & 18,2 & 17,6 \\
\hline 9. Carcastillo & 18,7 & 17,8 & 6,2 & 6,7 & 22,8 & 18 & 25 & 28,3 & 18,2 & 17,7 \\
\hline 10. Fitero ... & 15,6 & 10,9 & 4,1 & 1,3 & 19 & 8,9 & 28,1 & 23,7 & 15,4 & 11,2 \\
\hline
\end{tabular}

(1) Porcentaje de días de precipitación.

(2) Porcentaje de precipitación total.

El día 18 de diciembre de 1983 hubo situación del Oeste lluviosa. La corriente zonal descendió en latitud y el anticiclón de las Azores se vio desplazado hacia posiciones más meridionales, cercanas al paralelo $35^{\circ}$. En la topografía de 300 milibares un chorro del Oeste, con eje entre Madrid y Gibraltar y velocidad de cién nudos, atraviesa la Península. En la topografía de 500 milibares una borrasca con eje NW-SE, envía una corriente del Oeste. En superficie la borrasca se sitúa en Irlanda y un sistema frontal cálido y frío atraviesa nuestra zona (Mapa 6).

Las comarcas Navarras se comportan de manera diferente ante el flujo del oeste con sus variantes WNW y WSW de acuerdo con la orientación orográfica. El cielo está cubierto de nubes bajas, estratos y estratocúmulos, y viento fuerte de segundo y tercer cuadrante. Se pueden distinguir tres zonas lluviosas en Navarra: Pirineos, Cuencas Intermedias y Navarra Media Occidental. Los Pirineos representan elevaciones más altas en su parte oriental con valles transversales opuestos al flujo y las precipitaciones son altas (Eugui $40 \mathrm{~mm}$, Abaurrea Alta $51 \mathrm{~mm}$ ). Las Cuencas Intermedias, Orientadas zonalmente y paralelas al flujo, registran importante cantidad de lluvia (Alsasua 47,1 mm, Pamplona 37,1 mm). Por último, Navarra Media Occidental también favorable a esta situación, recibe cantidades elevadas (Alloz $52 \mathrm{~mm}$, Mendigorría 16,5 mm).

En Navarra Húmeda desciende considerablemente (Articutza 17,6 milímetros, Sumbilla 10,6 mm). En el resto, Navarra Media y Ribera, las 
Mapa n. ${ }^{\circ}$ 6.-Situación del W. 18-12-1983.

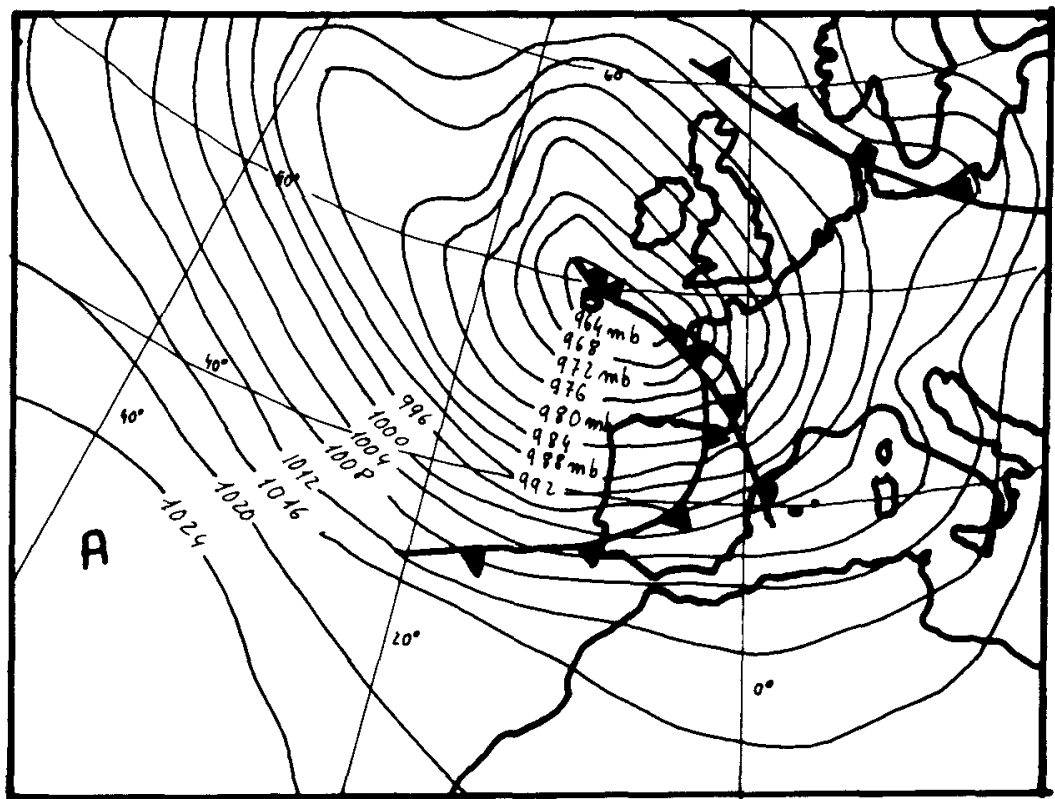

12 h.-Superficie.

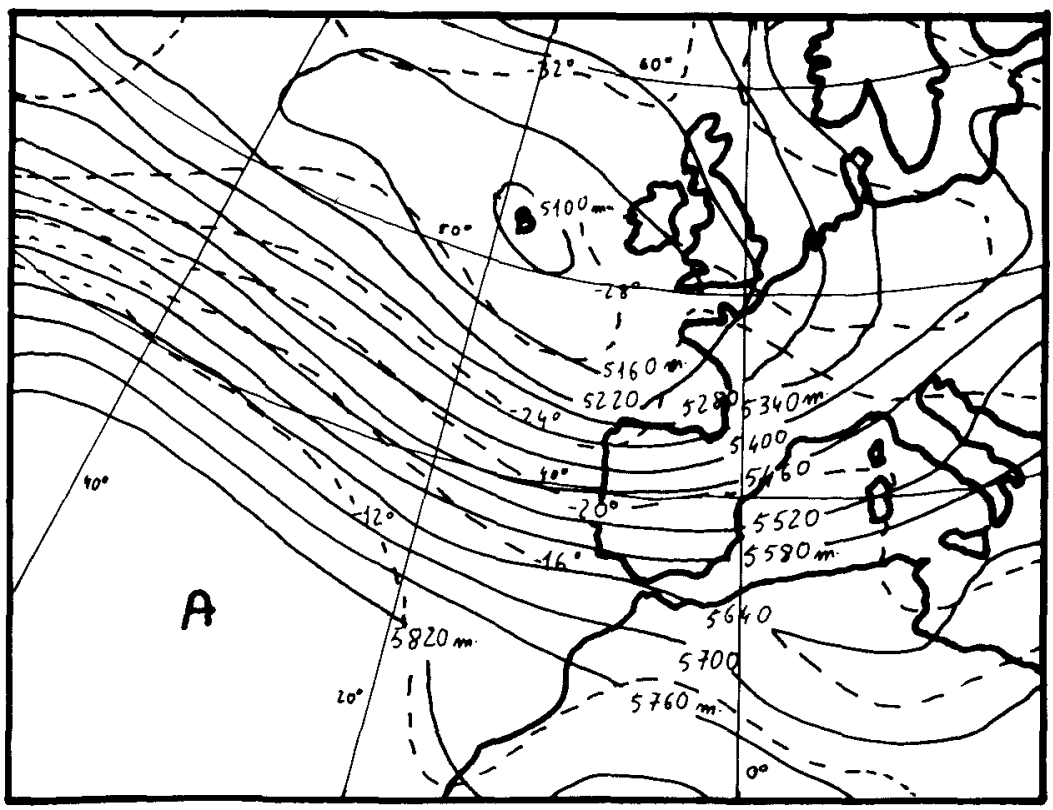

12 h. $-500 \mathrm{mb}$. 
lluvias son inferiores (Olite 3,2 $\mathrm{mm}$, Carcastillo $1,5 \mathrm{~mm}$ ). En definitiva, lluvias generales en Navarra, muy intensas en "la Montaña Navarra" cuando la corriente en chorro atraviesa nuestra Comunidad.

\section{SITUACIÓN DEL OESTE/ANTICICLÓNICO (W/ANT)}

Este tipo de situaciones suelen ser poco frecuentes y poco lluviosas en Navarra, debido a su carácter de altas presiones. Sin embargo hay varias situaciones dinámicas que pueden originar lluvias, principalmente en el Norte de Navarra. La primera de ellas es la llamada de anticiclón entrante, originada cuando al anticiclón Atlántico a modo de apófisis se extiende por el Cantábrico y por su flanco oriental llegan a nuestra área de estudio masas de aire marinas inestables, que en contacto con las montañas del Norte de Navarra pueden originar liuvias de intensidad ligeramente moderada. Otra situación lluviosa se desarrolla con un tiempo anticiclónico en superficie y una colada fría en el Mediterráneo, que da lugar a inestabilidad en nuestra área de estudio. En definitiva, son situaciones marginales con el denominador común de altas presiones y con circulación del Oeste en altura de poca intensidad, por lo que las precipitaciones son escasas y normalmente tan sólo originan un aumento de nubosidad.

Esta situación proporciona más porcentaje de días de lluvia en $\mathrm{Na}$ varra Húmeda y en los Pirineos Centrales. Los valores son inferiores en los Pirineos Orientales y en las Cuencas del Araquil y Pamplona más alejadas del Cantábrico. Al sur de las Sierras Exteriores los valores descienden y se sitúan en posiciones cercanas al 3 por 100 de dias de lluvia. La aportación al total de precipitaciones anuales todavia registra porcentajes más bajos que dan una idea de la escasa intensidad pluviométrica. En los Valles Húmedos aporta la mayor cantidad de lluvia, se reduce en los Pirineos y en las Cuencas Intermedias y al Sur de las Sierras Exteriores representa poco más del 1 por 100.

La estación invernal es la más frecuente para dar lugar a precipitaciones con situaciones del Oeste-anticiclónico, seguida de otoño y de primavera. En verano apenas si aparece, dada la poca fuerza de la corriente en chorro en altura (Cuadro VIII).

El día 24-5-83 hubo situación del Oeste-anticiclónico. En el mapa de 500 milibares se observan bajas presiones de orientación WNW-ESE que se extienden desde las proximidades de Islandia hasta el Norte de Italia, pasando por las Islas Británicas. Entre ambos centros de acción circula 
CUADRO VIII. PORCENTAJE DE DÍAS DE PRECIPITACIÓN Y DE PRECIPITACIÓN TOTAL QUE APORTA LA SITUACIÓN W/ANT. (19831986)

\begin{tabular}{|c|c|c|c|c|c|c|c|c|c|c|}
\hline \multirow{2}{*}{ OBSERVATORIOS } & \multicolumn{2}{|c|}{ PRIMAVERA } & \multicolumn{2}{|c|}{ VERANO } & \multicolumn{2}{|c|}{ OTOÑO } & \multicolumn{2}{|c|}{ INVIERNO } & \multicolumn{2}{|c|}{ ANUAL } \\
\hline & (1) & (2) & $(1)$ & (2) & (1) & (2) & (1) & (2) & (1) & (2) \\
\hline 1. Articutza & 6,2 & 4,6 & 3 & 0,8 & 12,1 & 5,1 & 8,4 & 4,9 & 7,4 & 3,9 \\
\hline 2. Sumbilla . & 4,9 & 3,5 & 2,3 & 0,1 & 8,4 & 2,8 & 8,5 & 4,1 & 6,1 & 2,6 \\
\hline 3. Eugui-Esteribar & 5,5 & 3,3 & 2,4 & 0,9 & 10 & 2,9 & 8,5 & 3,9 & 6,6 & 2,7 \\
\hline 4. Abaurrea Alta .... & 3,3 & 1,2 & 2,3 & 0,4 & 5,1 & 1,2 & 6,6 & 5,2 & 4,3 & 2,1 \\
\hline 5. Alsasua & 4,1 & 1,4 & 2,1 & 0,4 & 4,1 & 0,7 & 8,8 & 4,7 & 4,7 & 1,8 \\
\hline 6. Pamplona-Noain & 5,4 & 1,5 & 1,3 & 0,5 & 7,7 & 3,2 & 7,4 & 3,9 & 5,4 & 2,3 \\
\hline 7. Yesa ......... & 3,1 & 3,7 & 1,7 & 0,3 & 3,4 & 0,9 & 5,2 & 2,5 & 3,6 & 1,8 \\
\hline 8. Olite .......... & 3,1 & 1,6 & - & - & 5,8 & 0,9 & 5,2 & 2,6 & 3,5 & 1,3 \\
\hline 9. Carcastillo & 2,7 & 2,1 & - & - & 3,8 & 0,8 & 4,2 & 3,3 & 2,6 & 1,5 \\
\hline 10. Fitero .... & 2,7 & 3,1 & 2,1 & 5,6 & 5,1 & 0,8 & 4,2 & 3,1 & 3,5 & 3,2 \\
\hline
\end{tabular}

(1) Porcentaje de dias de precipitación.

(2) Porcentaje de precipitación total.

un flujo débil del Oeste. En 300 milibares una rama de la corriente en chorro se extiende zonalmente siguiendo el paralelo $50^{\circ}$ y otra es del WSW en el Norte de África. En superficie el anticiclón Atlántico con centro al Oeste de Galicia se extiende por la Península, sitúandose nuestra área de estudio en el flanco oriental. Asímismo una borrasca se encuentra alejada en el Centro de Europa. El débil flujo del Norte, unido a la débil circulación zonal en altura, va a dar lugar a precipitaciones solamente en el Cantábrico Oriental y Alto Ebro. En el resto de la Península el cielo está despejado y por lo tanto las precipitaciones ausentes (Mapa 7). Así pues se puede afirmar que este tipo de situaciones resultan a veces lluviosas y de un modo peculiar en nuestra área de estudio que se individualiza del resto de la Península.

Las Iluvias no son muy intensas en nuestra Comunidad. Destacan los Valles Húmedos y los Pirineos Centrales (Articutza 12,3 mm, Valcarlos $8,5 \mathrm{~mm}$ ); descienden en los Pirineos Orientales y en las Cuencas Intermedias (Abaurrea Alta 4,5 mm, Esparza de Salazar $3,5 \mathrm{~mm}$ ) y están ausentes en Navarra Media y Ribera.

En el Norte de Navarra el cielo está cubierto de nubes bajas, estratocúmulos y cúmulonimbos; brisa fuerte del NW; llueve todo el día con poca intensidad. En la Cuenca de Pamplona cielo cubierto de cúmulos y 
Mapa n. 7.-Situación del W/ANT. 24-5-1983.

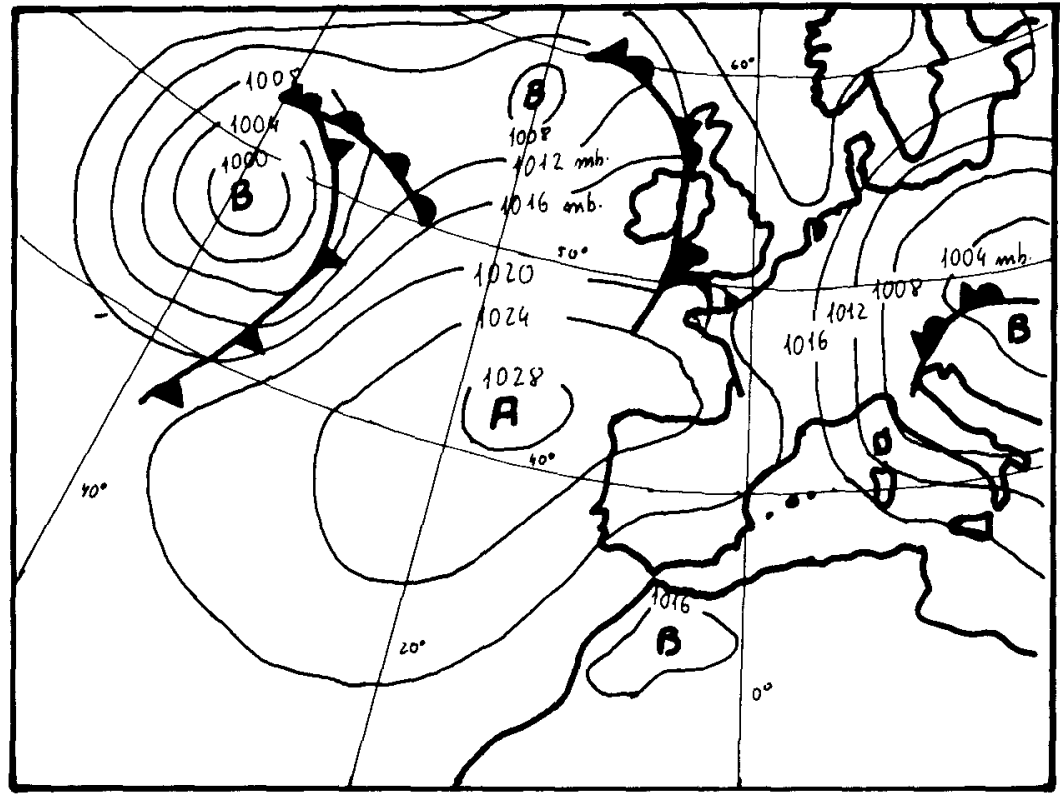

12 h.-Superficie.

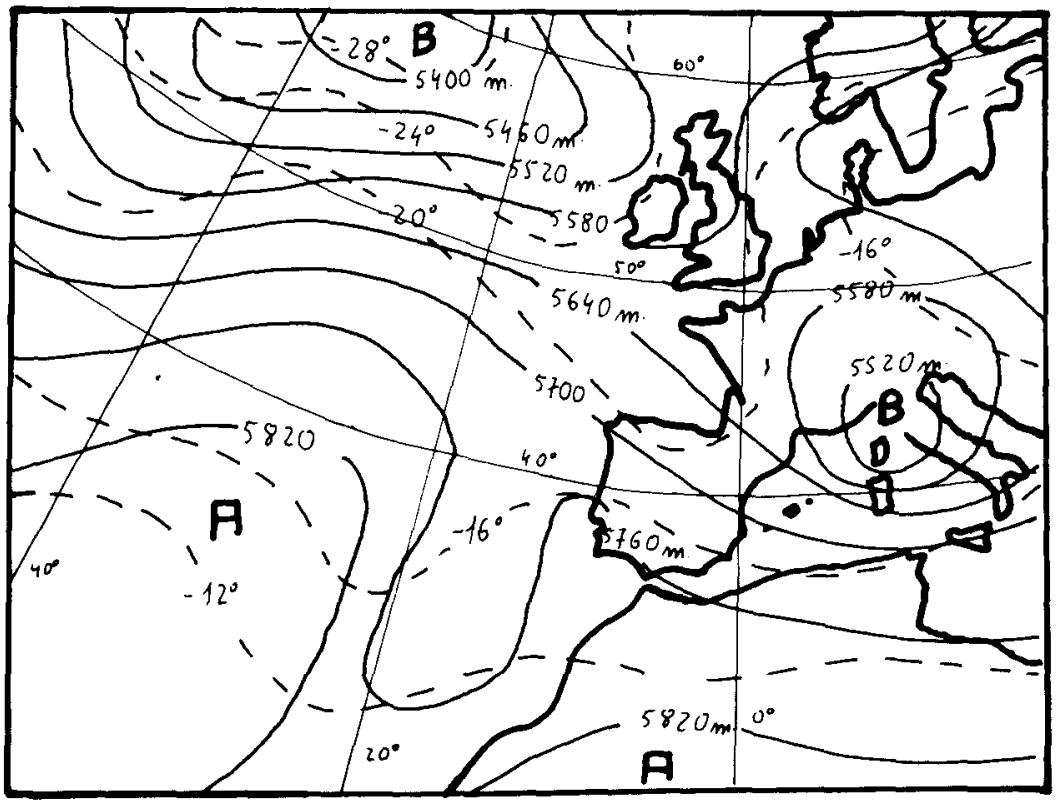

$12 h .-500 \mathrm{mb}$. 
estratocúmulos; brisa moderada del NNW. En el Sur de Navarra cielo también cubierto y ausencia de precipitaciones.

\section{SITUACIÓN DE BAJA FRIA (BJ)}

Las gotas frías tienen mucha importancia como situaciones lluviosas, siendo las que más días de precipitación originan y más cantidad aportan en la Cuenca de Pamplona, Navarra Media y Ribera. En efecto, cuando la circulación lenta de la corriente en chorro origina ondulaciones pronunciadas, puede desprenderse un embolsamiento frío y situarse en posiciones cercanas a Navarra, dando lugar a una inestabilidad importante que se traduce en precipitaciones. Sin embargo, no todas las bajas presiones a todos los niveles pueden dar copiosas precipitaciones, ni simultáneamente en todas las comarcas navarras, ya que es importante saber la posición de la misma, la temperatura de las masas de aire que se oponen, la intensidad de los movimientos verticales y la situación de las diferentes comarcas navarras respecto al frente de ataque. Las gotas frias siguen numerosas trayectorias; las que más afectan son las que se desprenden en el Atlántico, se situán en el Cantábrico y adoptan posiciones cercanas a Navarra: Pirineos, Depresión del Ebro e incluso centro de la Península.

Comparando con su frecuencia anual relativamente pequeña dan lugar a muchos días de lluvia, representando más del 20 por 100 de las jornadas lluviosas en la Cuenca de Pamplona, Navarra Media y Ribera. En el resto de Navarra los valores son altos y pasan normalmente del 15 por 100 , siendo las que más días proporcionan después de las situaciones del Noroeste y Oeste (Cuadro IX).

Las situaciones de baja fría contribuyen al total de precipitaciones con cantidades importantes. En la Cuenca de Pamplona, Navarra Media y Ribera aportan más del 20 por 100 de la lluvia anual, destacando los valores de la Ribera sobre Navarra Media y Cuencas; en todos estos observatorios se trata de la situación más lluviosa. En "la Montaña Navarra" después de las situaciones del Noroeste, es la que mayor cantidad de precipitación registra, destacando el Corredor del Araquil y Navarra Húmeda con porcentajes superiores al 20 por 100, seguidas de los Pirineos (Cuadro IX).

Verano, primavera y otoño son los períodos en que mayores porcentajes de días de lluvia y de precipitación total originan en Navarra, coincidiendo con las estaciones en que mayor tendencia hay a la existencia 
CUADRO IX. PORCENTAJE DE DÍAS DE PRECIPITACIÓN Y DE PRECIPITACIÓN TOTAL QUE APORTA LA SITUACIÓN DE BAJA FRÍA (BJ) (1983-1986)

\begin{tabular}{|c|c|c|c|c|c|c|c|c|c|c|}
\hline \multirow{2}{*}{ OBSERVATORIOS } & \multicolumn{2}{|c|}{ PRIMAVERA } & \multicolumn{2}{|c|}{ VERANo } & \multicolumn{2}{|c|}{ OTOÑO } & \multicolumn{2}{|c|}{ INVIERNO } & \multicolumn{2}{|c|}{ ANUAL } \\
\hline & (1) & (2) & (1) & (2) & (1) & (2) & (1) & (2) & (1) & (2) \\
\hline 1. Articutza & 19,9 & 18 & 21,7 & 43,7 & 12,8 & 14,9 & 5,9 & 5,4 & 14,3 & 20,5 \\
\hline 2. Sumbilla & 16,7 & 15,7 & 27 & 52,1 & 13 & 12,2 & 4,8 & 5,6 & 15,4 & 21,4 \\
\hline 3. Eugui-Esteribar & 16,6 & 14,9 & 26,8 & 47 & 13,7 & 12,5 & 4,9 & 4,3 & 15,5 & 19,7 \\
\hline 4. Abaurrea Alta & 18,4 & 13,2 & 31,8 & 37,9 & 16,1 & 12,6 & 4,4 & 2,5 & 17,7 & 16,6 \\
\hline 5. Alsasua & 16,8 & 14,9 & 33,3 & 55,5 & 14,5 & 10,1 & 7,3 & 10,7 & 18 & 22,8 \\
\hline 6. Pamplona-Noain & 17,4 & 19,8 & 37,2 & 52,8 & 18,8 & 19,2 & 4 & 4,1 & 19,3 & 24 \\
\hline 7. Yesa. & 22,6 & 20,4 & 42,4 & 56,4 & 22,7 & 21 & 4,6 & 4,3 & 23,1 & 25,5 \\
\hline 8. Olite & 20,1 & 18,6 & 41 & 71 & 19,8 & 30,4 & 5,1 & 5,1 & 21,5 & 31,3 \\
\hline 9. Carcastillo & 22,3 & 21,3 & 48 & 57,5 & 20,2 & 29,9 & 4,2 & 5,8 & 23,5 & 28,4 \\
\hline 10. Fitero & 26,6 & 34,9 & 46,9 & 69,8 & 25,3 & 37,9 & 5,3 & 20,7 & 26 & 40,8 \\
\hline
\end{tabular}

(1) Porcentaje de días de precipitación.

(2) Porcentaje de precipitación total.

de bajas frías. En invierno las bajas frías situadas en posiciones cercanas a Navarra suelen dar nevadas generales.

El día 12-5-85 hubo situación de baja fría en Navarra. A partir del día 10 se formó una baja fría desprendida de una vaguada atlántica que el día 12 se instaló en la vertical de nuestra área de estudio con una temperatura de $-24^{\circ}$. En la topografia de $500 \mathrm{mb}$ hay corriente moderada de componente Norte sobre Galicia y Sur de Baleares. En superficie las bajas presiones ocupan el Norte de África, la Península y Francia.

Hay un sistema complicado de borrascas centradas en el Norte de África, Gibraltar y París; la que más nos afecta es esta última, pues de la misma sale un frente frío que atraviesa Navarra. Sin embargo, conviene recordar, que quien dirige en este caso la circulación es la gota fría de altura (Mapa 8).

La gota fria afecta sobre todo a Navarra Húmeda, Corredor del Araquil y Cuenca de Pamplona. La lluvia tiene lugar a la noche con el paso del frente frío. Las máximas precipitaciones se dan en la Cuenca del Bidasoa, Corredor del Araquil y observatorios elevados próximos a las Sierras Exteriores (Sumbilla 40,5 mm, Alsasua 33,5 mm, Goñi 30,1 mm). En el resto (Valles Húmedos Occidentales, Valle del Baztán y Cuenca de Pamplona) la cantidad caída supera los veinte milímetros. En los Pirineos 
Mapa n. ${ }^{\circ}$ 8.-Situación BJ. 12-5-1985.

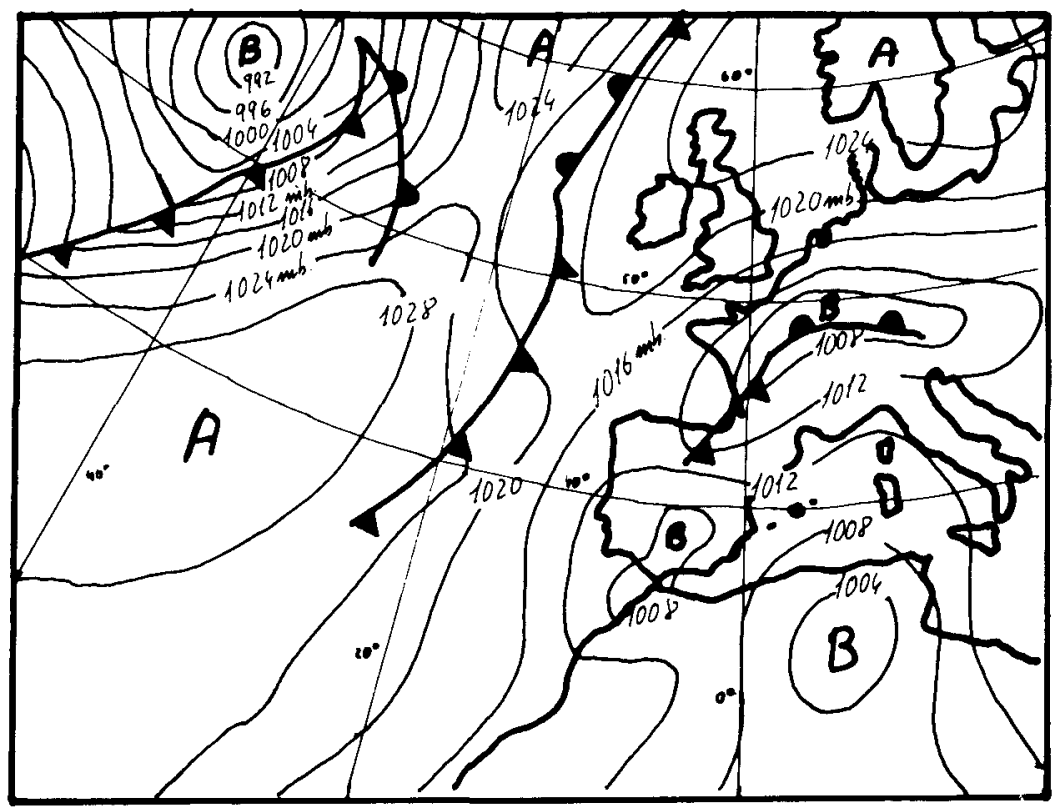

12 h.-Superficie.

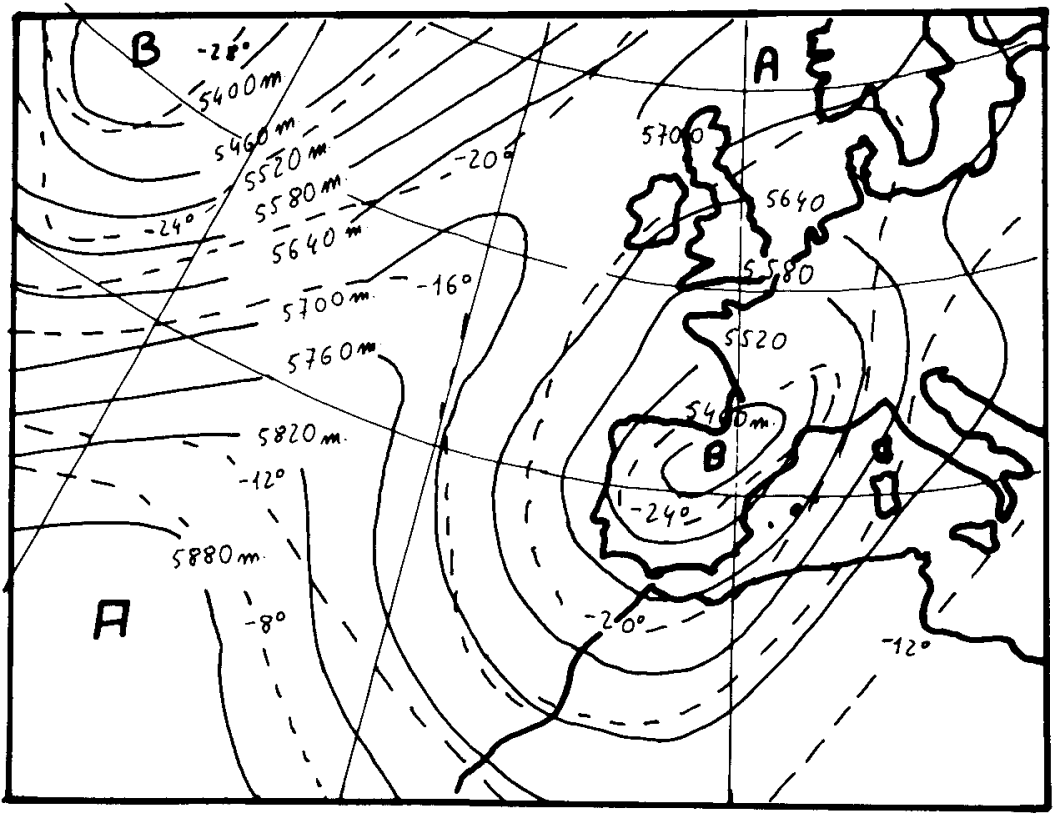

$12 \mathrm{~h} .-500 \mathrm{mb}$. 
la cantidad recogida es inferior por la situación más oriental. Solamente en los Centrales por su mayor apertura al Oeste se recogen cantidades apreciables (Eugui 13,4 mm y Roncesvalles $12 \mathrm{~mm}$ ). Superior a Pirineos $e$ inferior a los Valles Húmedos, es la cantidad de lluvia recogida en Navarra Media y Ribera. Aunque el comportamiento de las gotas frías es bastante caprichoso, se observa en nuestra Comunidad una mayor irrigación en la parte Occidental con respecto a la Oriental.

En el Norte de Navarra cielo nuboso con cúmulos y estratocúmulos en aumento al atardecer; humedad relativa alta; brisa moderada del SSW para rolar al NW. En la Cuenca de Pamplona cielo nubosos a la mañana y cubierto a la tarde; humedad relativa alta; caída de presión. En el Sur de Navarra cielo nuboso de cúmulos y estratocúmulos; viento encalmado con rachas de brisa fuerte al acercarse el frente frío. En toda Navarra llueve coincidiendo con el paso del frente frío.

\section{SITUACIÓN DE BAJA TÉRMICA (BT)}

Estas situaciones son propias de verano o meses próximos, principalmente mayo y septiembre, pertenecientes estos últimos a las estaciones equinociales. El excesivo calentamiento motivado por la radiación solar en el estío provoca un descenso de presión y da lugar a bajas presiones relativas que ocasionan movimientos convectivos y que sólo son perceptibles en los mapas de superficie. Estas bajas térmicas pueden producir fenómenos tormentosos en lugares concretos de Navarra, distribuidos sin orden, cuando traspasan la barrera de las altas presiones y obtienen amplio desarrollo vertical. Lo más normal es que no den lugar a precipitaciones, salvo si en altura aparece una vaguada o gota fría que reactiva el mecanismo de disparo.

Por lo tanto, estas situaciones dan lugar a pocos días de precipitación en Navarra destacando Navarra Húmeda, Media y Ribera con valores cercanos al 3 por 100 . En el resto de Navarra los valores son inferiores, mayores en los Pirineos Centrales y mínimos en puntos de Navarra Media. La contribución al total de precipitaciones es escasa por el carácter anticiclónico de las situaciones y se caracteriza por su marcada irregularidad (Cuadro $X$ ). En invierno este tipo de situaciones está ausente y en verano es cuando obtiene los mayores valores. En otoño y primavera aparece poco y en los meses cercanos al verano.

El 8 de julio de 1985 hubo situación de baja térmica en Navarra. En el mapa de $500 \mathrm{mb}$ existe una dorsal en el Norte de África y una baja poco profunda al NW de la Península; la temperatura en esta altura es 
CUADRO X. PORCENTAJE DE DÍAS DE PRECIPITACIÓN Y DE PRECIPITACIÓN TOTAL QUE APORTA LA SITUACIÓN BAJA TÉRMICA (BT) (1983-1986)

\begin{tabular}{|c|c|c|c|c|c|c|c|c|c|c|}
\hline \multirow{2}{*}{ OBSERVATORIOS } & \multicolumn{2}{|c|}{ PRIMAVERA } & \multicolumn{2}{|c|}{ VERANO } & \multicolumn{2}{|c|}{ OTONOO } & \multicolumn{2}{|c|}{ INVIERNO } & \multicolumn{2}{|c|}{ ANUAL } \\
\hline & (1) & (2) & (1) & (2) & (1) & (2) & (1) & (2) & (1) & (2) \\
\hline 1. Articutza & 1,3 & 0,2 & 8,4 & 2,7 & 4 & 0,8 & - & - & 3,4 & 0,9 \\
\hline 2. Sumbilla.... & 0,5 & 0,8 & 6,3 & 2,4 & 3,1 & 1,2 & - & - & 3,3 & 1,1 \\
\hline 3. Eugui-Esteribar & 1,3 & 0,4 & 6,5 & 0,9 & 2,5 & 0,6 & - & - & 2,6 & 0,3 \\
\hline 4. Abaurrea Alta & 0,5 & 0,1 & 4,7 & 2,2 & 2,5 & 1,1 & - & - & 1,9 & 0,8 \\
\hline 5. Alsasua & 1 & 0,4 & 3,1 & 0,6 & 2,4 & 1,1 & - & - & 1,6 & 0,5 \\
\hline 6. Pamplona-Noain & 0,5 & 0,4 & 5,1 & 0,9 & 1,7 & 3,1 & - & - & 1,8 & 1,1 \\
\hline 7. Yesa ............ & 1,6 & 0,4 & 10,2 & 5,6 & 2,3 & 2,1 & - & - & 3,5 & 2 \\
\hline 8. Olite $\ldots \ldots \ldots \ldots$ & 0,8 & 0,3 & 8,2 & 1,6 & 3,5 & 2,4 & - & - & 3,2 & 1,1 \\
\hline 9. Carcastillo $\ldots \ldots \ldots$ & 0,9 & 0,5 & 6,2 & 3,3 & 5,1 & 2,7 & - & - & 3 & 1,6 \\
\hline 10. Fitero $\ldots \ldots \ldots \ldots$ & 0,4 & 0,1 & 4,1 & 1,6 & 2,5 & 1,6 & - & - & 1,9 & 0,8 \\
\hline
\end{tabular}

(1) Porcentaje de dias de precipitación.

(2) Porcentaje de precipitación total.

de $-12^{\circ}$. En superficie el gradiente sobre la Península es débil; en el Atlántico existe un anticiclón y bajas relativas en el centro de la Península (Mapa 9).

La presencia en altura de una colada fría débil va a dar lugar a precipitaciones escasas en Navarra en forma de tormentas, destacando "la Montaña Navarra" (Articutza, 6,8 mm; Roncesvalles, $2,5 \mathrm{~mm}$ ). En la depresión del Ebro las lluvias son escasas o inexistentes. En el Norte de Navarra cielo cubierto de estratocúmulos y altostratos; viento débil con rachas de brisa fuerte del SSW. En la Cuenca de Pamplona cielo más despejado que en el Norte; viento flojo de segundo cuadrante. En el Sur de Navarra cielo parcialmente cubierto de cúmulosnibos que no llegan a dar tormentas más que en puntos muy concretos y con precipitación débil; viento en calma o moderado del NW.

\section{SITUACION DE PANTANO BAROMÉTRCIO (PB)}

A lo largo del año se observan días en que el gradiente bárico sobre la Península es inexistente, sin isobaras o a lo sumo una que la atraviesa con una presión media; en altura normalmente existe una dorsal, pero a 
Mapa n.o 10.-Situación PB. 22-5-1985.

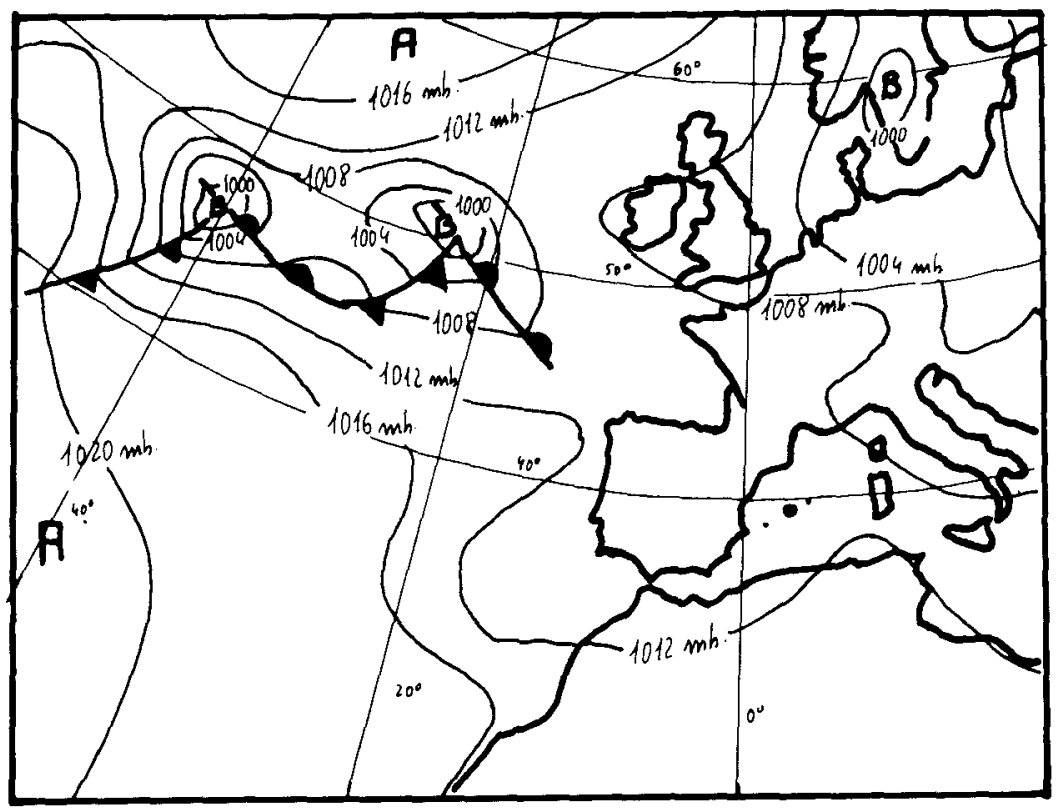

12 h.-Superficie.

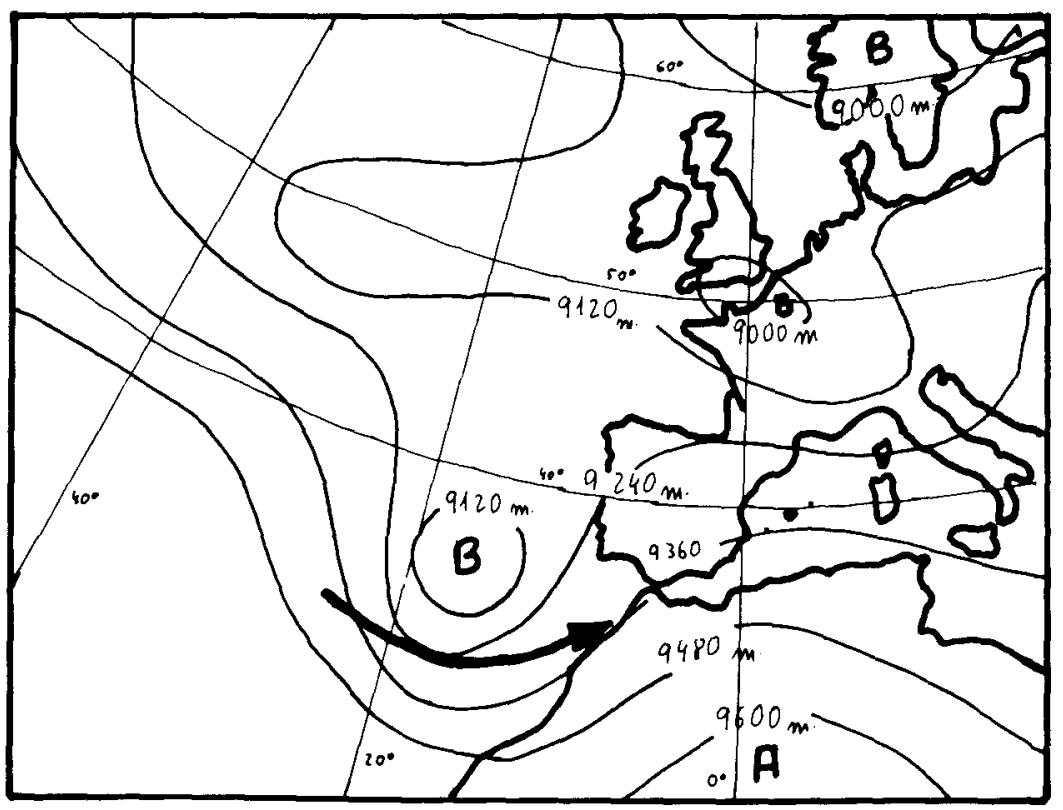

$12 \mathrm{~h} .-300 \mathrm{mb}$. 
veces en sus proximidades puede aparecer alguna colada fría que da lugar a inestabilidad de tipo tormentoso.

Al igual que lo que ocurría con las bajas térmicas, solamente si los movimientos convectivos originados con esta situación logran pasar la barrera de la subsidencia anticiclónica habrá precipitaciones y éstas se sucederán de un modo irregular. En la mayor parte de los observatorios navarros proporcionan porcentajes cercanos al 3 por 100 de los días de precipitación anual.

Contribuyen con porcentajes bajos al total de precipitaciones, que oscilan entre el 1 y 2 por 100, con la única excepción del enclave de Carcastillo que supera el 8 por 100 (Cuadro XI).

El día 9 de agosto de 1983 hubo una situación de pantano barométrico lluviosa en Navarra. Del 6 al 10 una depresión fría en altura si situó en el Cantábrico en posición cercana a nuestra área de estudio, mientras en superficie la diferencia de presión era mínima. El día 9, en el mapa de $500 \mathrm{mb}$, se observa que la baja fría se debilita, se alarga en dirección ENE-WSW, se centra al Oeste de Galicia y por su flanco oriental comprende nuestra Comunidad; la temperatura en el centro de la baja es de $-12^{\circ}$. Paralelamente una dorsal se coloca entre el Golfo de Cádiz y Baleares. En superficie el gradiente bárico en nuestra Península es muy pequeño. Así pues, se trata de una situación de pantano barométrico con

CUADRO XI. PORCENTAJE DE DÍAS DE PRECIPITACIÓN Y DE PRECIPITACIÓN TOTAL QUE APORTA LA SITUACIÓN DE PANTANO BAROMÉTRICO (PB) (1983-1986)

\begin{tabular}{|c|c|c|c|c|c|c|c|c|c|c|}
\hline \multirow{2}{*}{ OBSERVATORIOS } & \multicolumn{2}{|c|}{ PRIMAVERA } & \multicolumn{2}{|c|}{ VERANO } & \multicolumn{2}{|c|}{ OTOÑO } & \multicolumn{2}{|c|}{ INVIERNO } & \multicolumn{2}{|c|}{ ANUAL } \\
\hline & (1) & (2) & (1) & (2) & (1) & (2) & (1) & (2) & (1) & (2) \\
\hline 1. Articutza & 1,3 & 0,6 & 8,4 & 5,1 & 1,3 & 0,1 & - & - & 2,8 & 1,4 \\
\hline 2. Sumbilla & 1,5 & 0,4 & 9,5 & 6,1 & 0,8 & 0,1 & - & - & 2,9 & 1,6 \\
\hline 3. Eugui-Esteribar & 1,7 & 0,9 & 8,9 & 8,7 & 3,1 & 0,5 & - & - & 3,4 & 2,5 \\
\hline 4. Abaurrea Alta & 2,2 & 1,2 & 7,1 & 4,1 & 1,6 & 0,6 & - & - & 3,1 & 1,5 \\
\hline 5. Alsasua ..... & 1 & 0,7 & 7,3 & 9,3 & 1,6 & 0,5 & - & - & 2,5 & 2,6 \\
\hline 6. Pamplona-Noain & 1,6 & 3,2 & 9 & 5,2 & 1,7 & 0,2 & - & - & 3,1 & 2,1 \\
\hline 7. Yesa . & 3,9 & 4,1 & 8,5 & 5 & 1,1 & 0,1 & - & - & 3,4 & 2,3 \\
\hline 8. Olite & 3,9 & 7 & 9,8 & 4,3 & 1,1 & 0,1 & 一 & - & 3,7 & 2,8 \\
\hline 9. Carcastillo $\ldots \ldots \ldots$ & 5,3 & 6,7 & 14,6 & 24,8 & 2,5 & 0,7 & - & - & 5,6 & 8,1 \\
\hline 10. Fitero & 4,6 & 1,3 & 6,1 & 2,7 & 2,5 & 0,7 & - & - & 3,3 & 1,2 \\
\hline
\end{tabular}

(1) Porcentaje de dias de precipitación.

(2) Porcentaje de precipitación total. 
presencia de una colada fría en altura, que es precisamente la que va a crear la inestabilidad (Mapa 10).

En general, en toda Navarra se producen tormentas. En Navarra Húmeda se recoge poca cantidad; en cambio los Pirineos, sobre todo en los Centrales, las precipitaciones son más altas (Valcarlos, $24,3 \mathrm{~mm}$; Urzainqui, $11 \mathrm{~mm}$ ). En las Cuencas Intermedias disminuye la cantidad recogida (Alsasua, 6,3 mm; Noain, 2,4 mm), para aumentar en Goñi (16,7 $\mathrm{mm}$ ) observatorio bien expuesto, situado en las Sierras Exteriores. En Navarra Media la diferencia se deja sentir entre los puntos bien orientados a este flujo del SW en altura (Alloz, $25 \mathrm{~mm}$ ) y las zonas más llanas (Olite, $3,3 \mathrm{~mm}$ ). Finalmente, en la Ribera también se producen tormentas (Carcastillo, 11,5 mm; San Adrián, $5 \mathrm{~mm}$ ).

En el Norte de Navarra el cielo está cubierto de nubes bajas cúmulos y estratocúmulos con nubes medias altocúmulos; viento en calma o débil del SW. En la Cuenca de Pamplona el cielo está cubierto de estratocúmulos y cúmulonimbos; viento en calma con rachas de brisa moderada del NNW. En el Sur de Navarra cielo cubierto con nubes bajas y medias; brisa moderada del ESE o SE.

\section{CONCLUSIÓN}

Navarra, tierra de contrastes comarcales acusados en relación con su extensión, también lo es en cuanto a las situaciones atmosféricas variadas que originan las precipitaciones. Sin duda, la situación latitudinal de la Comunidad Navarra en el Cantábrico Oriental y la disposición del relieve navarro representado por las montañas del Norte de Navarra, los Pirineos Centrales y Orientales, la cadena divisoria Velate-Azpiroz y las Sierras Exteriores, unido a la variedad topográfica (valles de escasa altitud, valles pirenaicos con orientación N-S, Cuencas Intermedias de orientación zonal, somontanos de Navarra Media y Depresión del Ebro), confieren a nuestro territorio unas características peculiares con notables diferencias entre unas comarcas y otras, patentes en las situaciones atmosféricas lluviosas.

En "Navarra Húmeda" las advecciones del Noroeste resultan las más activas con valores que superan la tercera parte del total de lluvias en algunos observatorios, seguidas de las bajas frías, que superan la quinta parte. Las situaciones del Norte son muy efectivas y proporcionan más del 15 por 100 de la precipitación total. Las del Oeste, por el contrario, si bien proporcionan algo más del 10 por 100 de la lluvia total, dan 
Mapa n. 9.-Situación BT. 8-7-1985.

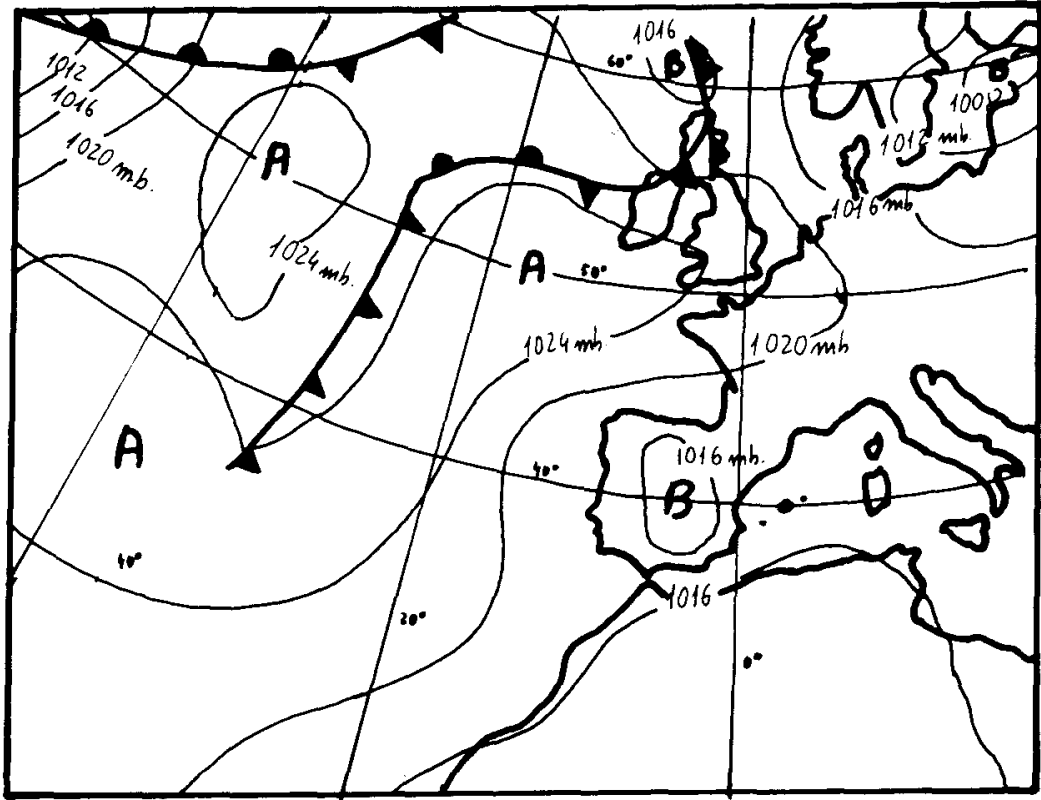

12 h.-Superficie.

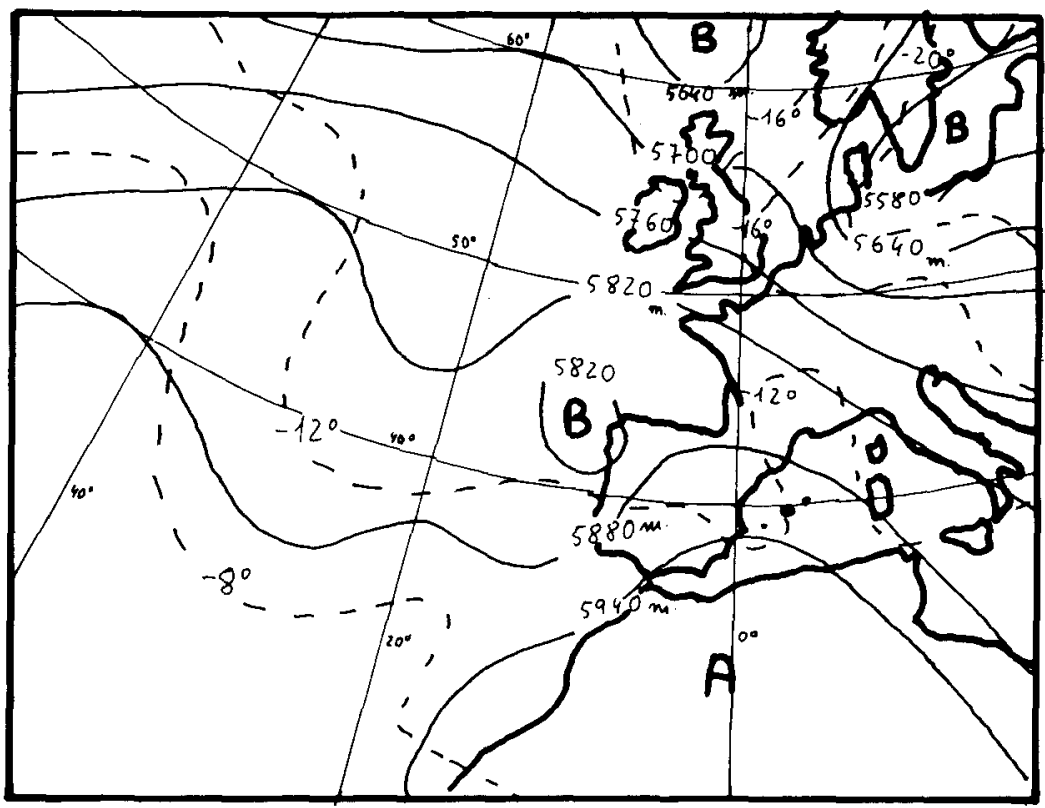

$12 \mathrm{~h} .-500 \mathrm{mb}$. 
los valores más bajos de todas las comarcas. Es necesario destacar la poca efectividad de las situaciones del Sudoeste. Dentro de la escasez general, las situaciones NE y W/ANT, es en esta zona donde más cantidad de lluvia aportan.

Por lo tanto, la posición de este sector, próximo al Cantábrico y en los primeros contrafuertes montañosos opuestos a los flujos del Noroeste y del Norte, da lugar a la obtención de numerosas precipitaciones con situaciones de primer y cuarto cuadrante, junto con las bajas frías siempre activas. Por el contrario, las situaciones meridionales, advecciones del Sudoeste, tienen escaso valor por su ubicación a sotavento de la Cadena Divisoria. Así pues los años en que predominen las situaciones meridionales (otoño-invierno 88-89 y 89-90) en exceso, se pueden dar riesgos de sequía.

En los “Pirineos», al igual que en Navarra Húmeda, siguen siendo las advecciones del Noroeste las más lluviosas. Las situaciones del Norte originan más precipitaciones en los Pirineos Centrales, que presentan un comportamiento parecido a los Valles Húmedos, que en los Pirineos Orientales, en donde se hace patente el efecto pantalla de la Cadena Pirenaica, más alta en estos. Este sector difiere del anterior en las mayores lluvias que proporcionan las situaciones meridionales del Sudoeste, hecho más apreciable en los Pirineos Orientales, lugar de obligado ascenso a las masas de aire de esta procedencia. Las bajas frías y las situaciones del Oeste son bastante lluviosas.

La "Cuenca de Pamplona" marca la transición de un medio oceánico al mediterráneo, obteniendo caracteres de ambos. Las situaciones del Noroeste y del Norte, si bien son todavia bastante activas, experimentan una reducción a la hora de contribuir al total de precipitaciones, a la vez que aumentan las situaciones del Sudoeste y las del Sudeste.

Finalmente en "Navarra Media y Ribera", las diferencias con respecto a Navarra Húmeda y a los Pirineos es amplia. En efecto, las situaciones de primer y cuarto cuadrante descienden en cuanto a la aportación de precipitaciones, mientras las del Sudoeste y las bajas frías son dominantes. Aparece así un nuevo régimen de lluvias muy diferenciado en que predominan las situaciones de tormenta y bochorno húmedo, en contraste con los aguaceros del Norte y del Noroeste más propios de "la Montaña Navarra».

En definitiva, hay que reiterar una vez más la variedad existente en nuestra Comunidad que da lugar a regímenes de precipitaciones diferentes, más perceptibles aquí por la compleja y quebrada orografía. Es cierto que asi como en otras comunidades españolas la transición del Cantá- 
brico al Mediterráneo se hace bruscamente, en Navarra, debido a la poca altitud de la Cadena Divisoria, este paso se hace de un modo gradual, apareciendo multitud de contrastes visibles en las situaciones atmosféricas lluviosas. 


\section{BIBLIOGRAFIA}

Capel Molina, J. J., 1981: Los climas de España. Barcelona, Oikos-tau.

Creus Novau, J., 1986: "Climatología en Gran Atlas de Navarra", Geografía. Pamplona. Caja de Ahorros de Navarra.

Creus, J. y Puigdefabregas, J., 1978: "Influencia del relieve en la distribución de las precipitaciones máximas. Un ejemplo pirenaico", Cuadernos de Investigación, tomo IV, fasc. 1. Logroño, págs. 11-23.

Creus Novau, J., 1983: «El clima del Alto Aragón Occidental». Monografias de Estudios Pirenaicos, n. ${ }^{\circ} 109$. Diputación de Huesca.

Fernández García, L., 1980: “Diferenciación regional en función de las precipitaciones", Estudios Geográficos, 159, págs. 145-168.

HeSsinger, E., 1949: "La distribución estacional de las precipitaciones de la Península Ibérica", Estudios Geográficos, págs. 59-128.

Lines Escardo, A., 1981: Perturbaciones típicas que afectan a la Península Ibérica y precipitaciones asociadas. Madrid. INM.

MARTIN VIDE, J., 1987: Caracteristiques climatologiques de la precipitacio en la franja costera Mediterránea de la península lbérica. Barcelona. Generalitat de Catalunya.

MOUNIER, J., 1979: «Les origines du passage du domaine océanique au domaine mediterranéen dans la Peninsule lberique», Mediterranée, 3, págs. 3-19.

Pedelaborde, P., 1970: Introduction á l,étude scientifique du climat. Paris. SEDES.

PejenAute Goñl, J., 1989: «Los dias de precipitación elevada en Navarra y las situaciones atmosféricas que los originan", Notas y Estudios de Ciencias Sociales, 2, págs. 17-60.

Pejanaute GoÑl, J. 1989: Tipos de tiempo y clima de las comarcas navarras. Tesis doctoral (en prensa). Madrid. Universidad a Distancia.

QueredA, J., 1989: La ciclogénesis y las gotas frias del Mediterráneo occidental. Diputación de Castellón. 
Ruiz Urrestarazu, E., 1982: La transición climática del Cantábrico Oriental al Valle Medio del Ebro. Vitoria. Diputación Provincial de Alava. URIARTE, A., 1983: El régimen de precipitaciones en la costa $N W$ y $N$ de la península lbérica. San Sebastián. Caja de Ahorros de Guipúzcoa. 